\title{
Utilization of centrate for the outdoor production of marine microalgae at pilot-scale in flat-panel photobioreactors
}

\author{
Romero-Villegas G.I. ${ }^{1}$, Fiamengo M. ${ }^{2}$, Acién Fernández F.G. ${ }^{1}$, Molina Grima E. ${ }^{1}$
}

${ }^{1}$ Department of Chemical Engineering, University of Almería, Ctra. Sacramento, s/n, 04120

La Cañada de San Urbano Almería, Spain

${ }^{2}$ Dipartimento Di Scienze Della Vita E Biotecnologie, Università degli Studi di Ferrara, Via Savonarola, 9, 44121 Ferrara FE, Italia

Keywords: Marine microalgae; centrate from anaerobic digestion; nitrogen removal; phosphorus removal; flat-panel photobioreactors 


\begin{abstract}
The outdoor production of marine microalgae biomass in pilot scale flat panels photobioreactors, under not sterile conditions and using centrate as nutrients source, was studied. Experiments were performed modifying the centrate percentage, dilution rate and orientation of the photobioreactors. The strain Geitlerinema sp. was that one prevailing independently of the culture conditions. The higher productivity of $47.7 \mathrm{~g}_{\text {biomass }} \cdot \mathrm{m}^{-2} \cdot \mathrm{day}^{-1} \mathrm{dry}$ weight and photosynthetic efficiency of $2.8 \%$, was achieved when using $20 \%$ centrate and a dilution rate of 0.3 day $^{-1}$, whatever the orientation of the reactor, maximal nutrient removal capacities of $82 \%, 85 \%$ and $100 \%$ for carbon, nitrogen and phosphorus being obtained. Under non-optimal conditions up to $80 \%$ of the nitrogen and $60 \%$ of the phosphorus were lost by stripping and precipitation, respectively. Carbohydrates was the major component of the biomass followed by proteins and lipids. These results support the possibility to produce microalgae biomass below $0.59 € / \mathrm{kg}$, useful to produce biofertilizers and animal feed.
\end{abstract}




\section{Introduction}

Microalgae have been extensively studied over recent decades due to its capacity to produce great amounts of biomass for different purposes such as pharmaceuticals, cosmetic, nutrition and animal feeding, in addition to bio-composites, biofertilizers and biofuels. However, at present, the cost of production of microalgae is still excessive with respect to the sale price, and only allow their commercialization as product for human and animal consumption. Thus, for a 100 ha plant size it was reported that the production cost can be reduced up to $5.96 € \cdot \mathrm{kg}^{-}$ ${ }^{1}$ using flat-panel photobioreactors (FP-PBRs) (Norsker et al., 2011). On this cost the utilization of pure $\mathrm{CO}_{2}$ and fertilizers represent up to $30 \%$ of the total production cost, thus to minimize the microalgae production cost the coupling of microalgae production with $\mathrm{CO}_{2}$ capture from flue gases and with wastewater treatment processes is mandatory. Industrial flue gases can be used instead of pure $\mathrm{CO}_{2}$, the cost of the former was estimated at $68 €$ 'ton ${ }^{1}$ instead of $247 € \cdot \operatorname{ton}^{-1}$ for pure $\mathrm{CO}_{2}$ (Pires et al., 2012). Concerning the nutrients, the nitrogen and phosphorous contained into urban wastewater (i.e. $60 \mathrm{mgN} / \mathrm{L}$ and $12 \mathrm{mgP} / \mathrm{L}$ ) can be enough to produce up to $1 \mathrm{~kg}_{\text {Biomass }} \cdot \mathrm{m}^{-3}$ wastewater, additionally saving the cost and energy consumption of treatment of this effluent of up to $0.2 € \cdot \mathrm{m}^{-3}$ and $0.5 \mathrm{kWh} \cdot \mathrm{m}^{-3}$ (Acién et al., 2016). Furthermore, wastewaters are rich in carbon, nitrogen and phosphorus along with other compounds which, if not adequately treated and removed, can contaminate rivers, oceans and underground aquifers (Caporgno et al., 2015).

The coupling of microalgae production and wastewater treatment is currently a hot topic on biotechnology of microalgae field. However, the utilization of sewage imposes that only freshwater microalgae can be produced, to produce marine microalgae the utilization of "nutrients-rich" wastewaters being necessary. In this case the utilization of centrate from 
wastewaters treatment plant as nutrients source for the production of marine microalgae has been previously demonstrated at laboratory scale and including using tubular PBRs (Ledda et al., 2015; Sepúlveda et al., 2015). However, tubular PBRs are too expensive and consuming too much energy to achieve low production cost, the utilization of FP-PBRs being recommendable for this objective (Norsker et al., 2011; Tredici et al., 2015).

In addition to the nutrients source and photobioreactor technology the other key aspect of the process is the strain to be produced. Although rigorous selection of microalgae strains can be performed on the basis of biochemical composition, growth rate, tolerance to adverse culture conditions, etc., the reality is that when wastewater is used as a source of nutrients and without any previous sterilization treatment, there is a potential risk of contamination of the cultures, then the study of the prevailing strains on the PBRs being highly of interest. Moreover, the presence of bacteria always take place although the proportion of these microorganisms with respect to microalgae biomass can be maintained at low values (Ferrero et al., 2012). Thus, the challenge is to find the adequate methods to manipulate the strains prevailing into the cultures and then to optimize the quality/composition of produced biomass whatever the strain to be produced.

The aim of this work is to study the production of marine microalgae in outdoor FP-PBRs using centrate from anaerobic digestion as nutrients source, determining the main factors influencing the strains prevailing into the cultures and then the quality/composition of produced biomass. Because wastewaters are used, the aim must be also to evaluate the performance of the system in terms of nutrients recovery. Experiments were performed at two different orientations (north-south and east-west) thus modifying the light availability, using different percentages of centrate into the culture medium (20-50\%) thus modifying the nutrients availability, and at two dilution rates (D) $\left(0.2\right.$ and 0.3 day $\left.^{-1}\right)$ thus modifying the 
metabolic status of the microalgal cells (growth rate/age of the cells and their related metabolisms). Thus, the challenge is to maximize the biomass productivity and to evaluate the biochemical composition of produced biomass for its further application in commodities market.

\section{Materials and methods}

\subsection{Microorganism and culture media}

The strain Nannochloropsis gaditana. Lubián CCMP 527 was initially used. Inoculum of Nannochloropsis g. was produced outdoors in 1001 bubble columns using Algal medium (Bionova, Santiago de Compostela, Spain. During the exponential growth phase, the inoculum was finally transferred to the FP-PBRs for the experiments. Culture medium for the FP-PBRs was prepared mixing natural seawater with different percentages of centrate. Centrate was collected from the wastewater treatment plant in Almería (Spain), directly from the bed filter used to separate the solids from the digestate liquid fraction, which is leaving the anaerobic digestion reactor. The centrate was free of solids particles (filtered of $100 \mu \mathrm{m}$ prior to mix it with seawater) and rich in ammonium, along with other compounds. The average composition of centrate used in this study is shown in Table 1 . The culture medium was prepared daily by mixing natural seawater with centrate, according to the centrate percentage set for the particular experiment. Additionally, phosphate was added to achieve a $\mathrm{N}: \mathrm{P}$ ratio of $5: 1$, which was previously demonstrated to be required to achieve optimal performance of the cultures and adequate removal of nitrogen (Ledda et al., 2015; Sepúlveda

et al., 2015). The culture medium was not sterilized or treated previously to be supplied to the PBRs, thus microalgae strains coming with the centrate were also allowed to grow into the cultures. Then, samples of the cultures were analysed twice a week to determine its 
biochemical and biological composition of the prevailing strains and percentage being identified.

\subsection{Photobioreactors and culture conditions}

Experiments were performed outdoors in a set of six FP-PBRs. Each reactor consisted of a disposable plastic bag placed between two steel frames. The steel frame dimensions were 1.7 $\mathrm{m}$ height $\times 0.096 \mathrm{~m}$ width $\mathrm{x} 2.5 \mathrm{~m}$ length, covering a land surface of $2.74 \mathrm{~m}^{2}$ (San Pedro et al., 2016). Each PBR had a working volume of 4001 , then the V/S ratio being $145 \mathrm{l} \cdot \mathrm{m}^{-2}$. Two different orientations were tested in order to determine the influence of the incidence of light with respect to the position of the sun. A set of three PBRs (3 x 400 1) were oriented eastwest (EW) and the other three PBRs were oriented north-south (NS). The PBRs were separated one meter each one, dummies being also located one meter from the external PBRs to homogenize the light availability for each one of the side-oriented PBRs. The plastic used for the bags was free-dispersant $200 \mu \mathrm{m}$ polyethylene with a transparency index of 0.95 in the photosynthetically active spectrum. The PBRs' inside walls were brushed three days a week with a $1.5 \mathrm{~m}$ long brush for avoiding the biofouling. Air was constantly injected into the reactor by an air compressor through a pipe located into the bottom to ensure adequate mixing and $\mathrm{O}_{2}$ degassing, also flue gases injection being performed by this pipe. The airflow rate entering to each PBR was $0.10 \mathrm{v} \cdot \mathrm{v}^{-1} \cdot \mathrm{min}^{-1}$ (FR4L72BVBN flow meters, Key Instruments, USA). The flue gas, with an average of $10.9 \%$ of $\mathrm{CO}_{2}$, was produced ondemand by a diesel-oil boiler connected to a compressor used to store the flue-gas in a 5001 tank at 2 bar for further utilization. A passive stainless-steel serpentine, connected to the outlet of the boiler, was used for cooling the flue-gas. To reduce the soot particulates content in the gas stream, the gas was filtered by three sequential cartridge filters $(1 \mu \mathrm{m})$ before being 
injected in the cultures. The flue gas was injected into the PBRs on demand for controlling the $\mathrm{pH}$ at 8 , at a constant flow rate of $0.01 \mathrm{v} \cdot \mathrm{v}^{-1} \cdot \min ^{-1}(\mathrm{FR} 4 \mathrm{~A} 41 \mathrm{BVBN}$ flow meters, Key Instruments, USA). Temperature-pH probes (5342 pH electrode, Crison Instruments S.A., Spain) were located at the top of the reactor and connected to a MM44 control-transmitter unit (Crison Instruments, Spain). Monitoring and control of the culture parameters was controlled by, and logged into, a PC control unit. The solar radiation received at horizontal surface was measured with a thermoelectric pyranometer connected to an AC-420 adapter (LP-02, Geónica S.A., Spain). The data logging and control system was developed by our research group using DaqFactory 5.8. (Azeotech Inc., USA).

Experiments were carried out in semi-continuous mode over summer season. Thus, fresh medium was supplied to the PBRs daily at the set D for each experiment, during the $4 \mathrm{~h}$ in the middle of the solar cycle, the same volume of culture being harvested. The PBRs were operated at two different $\mathrm{D}, 0.2 \mathrm{day}^{-1}$ and $0.33 \mathrm{day}^{-1}$. D represents the rate of flow of culture medium over the volume of culture in the bioreactor; i.e., depending of the D used, every day was harvested a $20 \%$ or a $30 \%$ of culture medium and at the same time, it was added the same amount of fresh culture medium Different percentages of centrate into the culture medium were essayed $(20 \%, 30 \%, 40 \%$ and $50 \%)$, using natural seawater to prepare it. The percentage of centrate determines the amount of nutrients daily provided to the PBRs, while the $\mathrm{D}$ determines the final biomass concentration into the culture at steady state (the continuous culture reaches "balanced growth" in which the levels of microorganisms, microorganisms products, media components, and waste products are constant (Pelczar et al., 1993)). Experiments were performed in two sets of three PBRs (i.e., in the six PBRs simultaneously, in triplicate). The average values from each set (3 x 4001$)$ of PBRs has been used. 


\subsection{Biomass concentration and quantum yield determination}

The biomass concentration $\left(\mathrm{C}_{\mathrm{b}}\right)$ was daily determined by measuring the absorbance of each sample at $750 \mathrm{~nm}$ (DR/4000 UV/Vis Spectrophotometer, HACH, USA) because at that wavelength there is less interference by pigments or other compounds. Spectrophotometric measurements were verified by dry weight determination twice a week by centrifuging 100 $\mathrm{ml}$ of culture for $15 \mathrm{~min}$ at $4500 \mathrm{rpm}$; washing the pellet to remove salts, again centrifuging the sample, finally the pellet was freeze-dried (LYOQUEST-55 Telstar Technologies, S.L. Spain) for $24 \mathrm{~h}$ and subsequently weighed and analysed. To determine the extinction coefficient of the biomass $\left(\mathrm{K}_{\mathrm{a}}\right)$ the average absorbance of each sample taken from the PBRs at wavelengths from 400 to $700 \mathrm{~nm}$ is divided by the biomass concentration $\left(\mathrm{C}_{\mathrm{b}}\right)$ and the cuvette light path ( $\left.\mathrm{P}_{\text {cuvette }}\right)$ (Eq. 1).

$$
K_{a}=\frac{A b s}{C_{b} \cdot P_{\text {cuvette }}}
$$

The volumetric productivity was calculated by multiplying biomass concentration $\left(\mathrm{C}_{\mathrm{b}}\right)$ by the set dilution rate (D) using Eq. 2.

$$
P b_{v o l}=C_{b} \cdot D
$$

The land areal productivity was calculated by multiplying the volumetric biomass productivity by the volume of the PBRs. The volume-surface ratio considered was calculated, taking into account the working volume of the reactor and the land surface occupied by it, which included the distance among reactors; dividing volumetric biomass productivity by land area, which included the distance among reactors using Eq. 3.

$$
P b_{\text {area }}=P b_{\text {vol }} \frac{V}{S}
$$




\subsection{Light availability and solar efficiency}

The average irradiance to which cells are exposed inside a culture $\left(\mathrm{I}_{\mathrm{av}}\right)$ is a function of irradiance in the absence of cells $\left(\mathrm{I}_{\mathrm{o}}\right)$, the biomass extinction coefficient $\left(\mathrm{K}_{\mathrm{a}}\right)$, the biomass concentration $\left(\mathrm{C}_{\mathrm{b}}\right)$ and the light path inside the reactor $(\mathrm{p})$. This can be approximated using Eq. 4 (Molina-Grima et al., 1997).

$$
I_{a v}=\frac{I_{0}}{\left(K_{a} \cdot p \cdot C_{b}\right)}\left(-\exp \left(-K_{a} \cdot p \cdot C_{b}\right)\right)
$$

Equation 4

Quantum yield $\left(\Psi_{\mathrm{E}}\right)$ is the amount of biomass generated from the unit of radiation absorbed by the culture. Since this represents the ratio of biomass generation to the absorbed photon flux, it can be calculated using Eq. 5 (Molina-Grima et al., 1997); where $\mathrm{Pb}_{\mathrm{vol}}$ stands for the volumetric biomass productivity and $\mathrm{F}_{\mathrm{vol}}$ for the photon flux absorbed by the volume unit. The photon flux absorbed through the reactor volume can be obtained from the average irradiance $\left(\mathrm{I}_{\mathrm{av}}\right)$ on a culture volume basis using Eq. 6 (Molina-Grima et al., 1997).

$$
\begin{array}{ll}
\Psi_{E}=\frac{P b_{v o l}}{F_{v o l}} & \text { Equation 5 } \\
F_{v o l}=I_{a v} \cdot K_{a} \cdot C_{b} & \text { Equation 6 }
\end{array}
$$

The maximum efficiency at which photosynthesis can convert solar energy into biomass (Photosynthetic efficiency) was calculated according to Eq. 7 (Molina-Grima et al., 1997), where $\mathrm{Q}_{\mathrm{b}}$ is the combustion heat; which is about $21.4 \mathrm{KJ} \cdot \mathrm{g}^{-1}$ (Molina-Grima et al., 1997).

$$
\begin{array}{ll}
\text { Photosynthetic efficiency }=\frac{P b_{v o l} \cdot Q_{b}}{F_{\text {vol }}} & \text { Equation } 7
\end{array}
$$




\subsection{Nutrient removal capacity and stripping}

Nitrogen and phosphorus removal efficiencies $\left(R_{e}\right)$ and removal capacities $\left(R_{c}\right)$ were calculated according to Eq. 8 and Eq. 9, where $\mathrm{C}_{0}$ is the element concentration at the inlet and $\mathrm{C}$ is the element concentration at the outlet of the cultures.

$$
\begin{array}{lr}
R_{e}=\frac{C_{0}-C}{C_{0}} \cdot 100 & \text { Equation 8 } \\
R_{C}=\left(C_{0}-C\right) \cdot D & \text { Equation 9 }
\end{array}
$$

Stripping is a physical phenomenon where a compound is removed from a liquid stream using a gas stream. The amount of nitrogen removed from the cultures by stripping was calculated by a mass balance between the inlet nitrogen with the culture and the outlet with the biomass and culture broth according to Eq. 10:

$$
\% N_{\text {Stripping }}=\frac{\left(\frac{R_{C}}{\left(R_{C}\right)-\left(P b_{v o l} \cdot \% N_{\text {biomass }} \cdot 1000\right)-(C \cdot D)}\right)}{R c} \quad \text { Equation } 10
$$

\subsection{Analytical methods}

For the analysis of the nitrogen, phosphorus and total carbon in the culture medium and supernatant, it was used the standard official methods approved by the Spanish Ministry of Agriculture. Nitrates were quantified using a spectrophotometer between 220 and $275 \mathrm{~nm}$. Ammonium was measured by the Nessler reaction method. Phosphate was measured by visible spectrophotometry through the phospho-vanado-molybdate complex. Total Inorganic Carbon (TIC), Total Organic Carbon (TOC) and Total Carbon (TC) were measured by the direct injection of samples, which were previously filtered, into a Shimadzu-5050A TOC analyser provided with an NDIR detector and calibrated with standard solutions of potassium phthalate. With regard to the biomass, freeze-dried biomass from each steady state was 
analysed. Lipids were determined gravimetrically from an extract obtained with chloroform:methanol $(2: 1)(\mathrm{v} / \mathrm{v})$. The protein content was determined using the modified Lowry method. Fatty acids were determined by gas chromatography.

Microalgal population analysis of counting and taxonomic identification were performed according to the Utermöhl method; briefly, the microalgae were preserved with formaldehyde to maintain sample viability, subsequently they were put in a cylindrical sedimentation chamber where they were counted and identified by inverted microscopy (Edler and Elbrächter, 2010)

\section{Results and Discussion}

Experiments were performed outdoors in a set of pilot scale FP-PBRs modifying (i) the orientation of the PBRs, (ii) the percentage of centrate into the culture medium, and (iii) the set $\mathrm{D}$. These assays were carried out in the summer season thus the environmental conditions as light and temperature remaining constant, with mean values of $1200 \mu \mathrm{E} \cdot \mathrm{m}^{-2} \cdot \mathrm{s}^{-1}$ and $25^{\circ} \mathrm{C}$ during daylight period. The composition of raw centrate and culture media obtained by mixing seawater with centrate as nutrients source are shown in Table 1. Considering the expected composition of microalgae biomass $(50 \% \mathrm{C}, 7 \% \mathrm{~N}, 1 \% \mathrm{P})$ it can be calculated that to

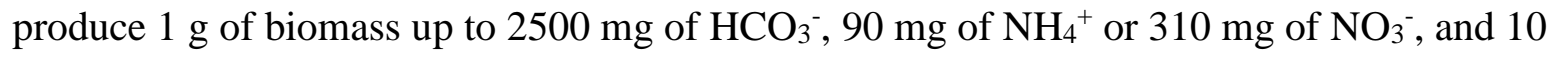
mg of $\mathrm{P}$ would be required, nevertheless, this composition varies between microalgae species. By comparing these values with the chemical composition of centrate it is observed as centrate contains much more ammonium than required to efficiently uptake the phosphorous and bicarbonates contained into the culture medium (Ledda et al., 2015; Sepúlveda et al., 2015). This is in terms of relative content, but in terms of magnitude the ammonium concentration also exceed that recommended to avoid inhibition by ammonium of $100 \mathrm{mg} \cdot \mathrm{l}^{-}$ 
${ }^{1}$ (Collos and Harrison, 2014). To solve the inhibition by ammonium toxicity, centrate was diluted with seawater to prepare the culture medium, whereas to solve carbon limitation the supply of $\mathrm{CO}_{2}$ on-demand is indispensable, by the same order, to avoid limitation of growth by this nutrient, the supply of additional phosphorous was needed (Sepúlveda et al., 2015). To maximize both the productivity of biomass, and the efficient recovery of nutrients contained in the culture medium, it is essential to operate at those conditions (Ledda et al., 2015). Thus, when supplying additional phosphorous to achieve a $\mathrm{N}: \mathrm{P}$ ratio of $5: 1$, a considerable increase in cell concentration were observed in the cultures compared to microalgal cultures in which standard Algal medium was used (Ledda et al., 2015; San Pedro et al., 2014; Sepúlveda et al., 2015). Furthermore, the elemental composition of the culture media used in this study shows a C:N:P average ratio of 100/126/19, while the C:N:P average ratio for the biomass was $100 / 20 / 2$. The elemental composition of $\mathrm{C}: \mathrm{N}$ : $\mathrm{P}$ in the culture medium, with respect to the biomass, shows that the culture medium was limited due to a carbon deficiency, thus the injection of $\mathrm{CO}_{2}$ supplied that carbon in the culture medium. In addition, the supply of additional phosphorous also allows avoiding limitation by this nutrient. Similar results has been reported in previous studies using tubular PBRs (Romero Villegas et al., 2017). In addition to major nutrients the centrate also provide other important elements for microalgal growth such as iron, calcium, potassium, etc., thus the supply of additional fertilizers or micronutrients being not required.

Concerning biomass productivity, results shows as steady states were achieved, in the same way for both PBRs orientation (NS, EW), when percentage of centrate into the culture medium was equal to or less than $40 \%$, when supplying $50 \%$ of centrate into the culture medium the cultures being close to washout (Figure 1). Anyway, results show as the increase of centrate percentage into the culture medium negatively affects the performance of the 
cultures, biomass concentration and productivity decreasing the higher the percentage of centrate was. This could be due to the presence of whatever toxic compound into the centrate, especially ammonium that including when supplying $20 \%$ of centrate to the culture medium achieve concentrations up to $146 \mathrm{mg}_{\mathrm{NH} 4} \cdot \mathrm{l}^{-1}$, higher than $100 \mathrm{mg}_{\mathrm{NH} 4} \cdot \mathrm{l}^{-1}$ reported to be toxic for different microalgae species (Collos and Harrison, 2014). Maximal biomass concentration up to $1.27 \mathrm{~g}_{\text {biomass }} \mathrm{l}^{-1}$ was achieved when utilizing the minimum percentage of centrate into the culture medium $(20 \%)$ at 0.2 day $^{-1}$ D. However, the maximal biomass productivity up to $0.32 \mathrm{~g}_{\text {biomass }} \mathrm{l}^{-1} \cdot \mathrm{day}^{-1}\left(47 \mathrm{~g}_{\text {biomass }} \cdot \mathrm{m}^{-2} \cdot\right.$ day $\left.^{-1}\right)$ was also achieved using culture medium containing $20 \%$ of centrate, but when the D was 0.3 day $^{-1}$, whatever the orientation of the PBRs (Figure 1). These results confirm that D has a major effect into the biomass concentration and productivity than the orientation of the PBRs, higher values being obtained when operating at 0.3 day $^{-1} \mathrm{D}$. The relevance of $\mathrm{D}$ in the productivity of microalgae cultures has been extensively reported and it is mainly related with the variation of light availability inside the PBRs when modifying the biomass concentration at different $\mathrm{D}$, whatever the type of photobioreactor used (Acién Fernández et al., 2013). Based on the above, it is important to mention that the dilution rate represents the rate of flow of culture medium over the volume of culture in the bioreactor; i.e., depending of the dilution rate used, every day, it was added a $20 \%$ or a $30 \%$ of fresh culture medium and at the same time the same amount of culture medium was harvested, which clarifies the culture medium allowing light to penetrate more easily at a greater distance from the surface or walls of the reactor. Concerning the orientation, it has been reported that EW is the optimal for FP-PBRs (Tredici et al., 2015). With NS orientation the PBRs intercept 5\% more radiation than horizontal systems on an annual basis, due to for latitudes above $35^{\circ} \mathrm{N}$ the orientation is favourable to NS, the higher the latitude the higher the increase in the solar radiation intercepted. On the contrary, for 
latitudes under $35^{\circ} \mathrm{N}$ the NS orientated PBRs intercept less radiation and the difference is more pronounced the closer to the equator (Sierra et al., 2008). Results here reported shows no effect of reactor orientation in biomass productivity in spite that in summer time EW oriented PBRs must to intercept more light than NS oriented PBRs, thus indicating that the cultures can be limited/damaged by other factors in addition to light availability as related with culture medium composition.

Concerning the biological composition of produced biomass samples were taken directly from the PBRs at steady state and analysed to identify the prevailing strains and relative percentage. The proportion of bacteria was always low as indicates the high dissolved oxygen values measured into the cultures including during night period (over $80 \%$ Sat.). Moreover, values of respiration rate of samples confirm that biomass was mainly composed by microalgae (data not shown). Regarding microalgae species, in spite that initially Nannochloropsis g. was inoculated (up to $30 \%$ of the total volume), at steady states the cultures were close to monoalgal cultures. However, one different strain was found and identify as Geitlerinema sp. (>98\%) also containing small percentage of Nannochloropsis $g$. Geitlerinema sp. is a blue-green cyanobacteria which can be found in a wide variety of habitats, including freshwater, brackish and thermal (Silva and Pienaar, 2000), moreover, as well as this study, it can be found in wastewater. Information about the cyanobacteria Geitlerinema sp. is very limited, however, it has been observed that these cyanobacteria can be found in sediments rich in organic matter and in hypertrophic water bodies (in both fresh and marine water) (Andrianasolo et al., 2005; Hašler et al., 2012; Jodlowska and Latala, 2013). It has been shown that this cyanobacteria has its maximal growth rate at $35^{\circ} \mathrm{C}$ (Latala and Misiewicz, 2000), which can explain its successful adaptability to outdoor conditions. Results shows as composition of the consortium prevailing into the PBRs was quite stable 
whatever the operation conditions (Figure 2). No influence of D into the percentage of Geitlerinema sp. was observed, the percentage of centrate only slightly modifying the relative proportion of both strains Geitlerinema sp. and Nannochloropsis g. Because the culture medium was not sterilized and the PBRs were operated open to the atmosphere, it was reasonable to expect contaminant strains into the cultures. However, the high final content of Geitlerinema sp. cultures obtained suggest that the culture medium used and the culture conditions set are favourable for this strain and, at the same time, they being negative for Nannochloropsis g. cells. This problem could be avoided or minimized if the culture medium is sterilized and closed PBRs are used (Ledda et al., 2016; Sepúlveda et al., 2015). Since it had been observed that monoalgal cultures of Nannochloropsis G. can be obtained in continuous mode in tubular PBRs, using a filtration step $(10,5$ and $1 \mu \mathrm{m})$ before entering to the PBRs, which also used centrate as the only source of nutrients (Romero Villegas et al., 2017). However, the utilization of tubular PBRs and sterilization steps can greatly increase the overall production cost (Acién et al., 2012).

Because the cultures were close to monoalgal cultures of Geitlerinema sp. the performance of this strain at the set experimental conditions can be compared with that obtained with other strains. Thus, results demonstrate that using centrate as nutrients source Geitlerinema sp. can be produced in open FP-PBRs, reaching biomass productivity values analogous to other strains, maximal productivity being achieved when using $20 \%$ of centrate, the cultures being washout when $50 \%$ of centrate was supplied to the culture medium. In tubular PBRs analogous results were obtained with Nannochloropsis g., maximal and minimal biomass productivities being achieved when centrate at $20 \%$ and $50 \%$ were used, respectively (Romero Villegas et al., 2017). In indoor studies, the maximal productivity of up to 0.4 g biomass $\mathrm{l}^{-1} \cdot$ day $^{-1}$ was achieved when using culture medium containing $50 \%$ of centrate and 
low light of $500 \mu \mathrm{E} \cdot \mathrm{m}^{-2} \cdot \mathrm{s}^{-1}$ (Sepúlveda et al., 2015), thus indicating that the combination of high ammonium and high sunlight can negatively affect to the cultures. In the same FP-PBRs and culture conditions that here used, but using standard culture media as Algal medium instead of centrate, a maximal biomass productivity of $0.17 \mathrm{~g}_{\text {biomass }} \cdot \mathrm{l}^{-1} \cdot \mathrm{day}^{-1}\left(24 \mathrm{~g}_{\text {biomass }} \cdot \mathrm{m}^{-2} \cdot \mathrm{l}^{-}\right.$ ${ }^{1}$ ) at a D of 0.35 day $^{-1}$ with Nannochloropsis $g$. was achieved (San Pedro et al., 2016). These results are including lower than that here reported with Geitlerinema sp. using centrate as nutrients source, thus confirming the higher performance of this strain versus Nannochloropsis $g$. in spite of the adverse composition of culture medium. However, maximal biomass productivity up to $0.36 \mathrm{~g}_{\text {biomass }} \cdot \mathrm{l}^{-1} \cdot \mathrm{day}^{-1}$ has been reported for Nannochloropsis g. cultures in FP-PBRs, this value being similar to that here reported (Rodolfi et al., 2009). Furthermore, studies of Nannochloropsis g. cultivated with fertilizers in analogous flat-plate glass PBRs (500 1) obtained maximal productivity values of 12.10 g biomass $\cdot \mathrm{m}^{-2} \cdot \mathrm{day}^{-1}$ at a D of $0.1 \mathrm{day}^{-1}$ (Richmond and Cheng-Wu, 2001), it representing only $13 \%$ of value here reported. Therefore, these data demonstrate that biomass productivity is not only a function of photobioreactor type used but also of strain, culture medium and operation conditions set, thus to define a single optimal process being almost impossible whatever the final target.

To evaluate the influence of set culture conditions into the optical properties of the biomass and light utilization efficiency the (i) extinction coefficient of the biomass, (ii) average irradiance, (iii) quantum yield and (iv) photosynthesis efficiency, were determined. Data shows as the optical properties, so the extinction coefficient of the biomass, greatly modifies as a function of centrate percentage into the culture medium and the orientation of the PBRs, the set $\mathrm{D}$ having a minor effect (Figure $3 \mathrm{~A}$ ). The extinction coefficient of the biomass increases with the percentage of centrate into the culture medium from $0.09 \mathrm{~m}^{2} \cdot \mathrm{g}^{-1}$ to 0.53 
$\mathrm{m}^{2} \cdot \mathrm{g}^{-1}$; however, the major increase was observed for the cultures developed in the FP-PBRs EW oriented, whereas in the cultures developed in the FP-PBRs NS oriented the extinction coefficient of the biomass only increase from $0.09 \mathrm{~m}^{2} \cdot \mathrm{g}^{-1}$ to $0.17 \mathrm{~m}^{2} \cdot \mathrm{g}^{-1}$. The increase of extinction coefficient of the biomass is usually related with an increase in the pigments content of the cell then reducing the light availability inside the culture, although it can be originated by different factors as age of the cells, nutrients availability, etc. (Molina-Grima et al., 1994). The average irradiance to which the cells were exposed in the cultures showed two different trends. In the EW oriented PBRs, the average irradiance reduces when the percentage of centrate increases from 20 to $40 \%$, from a maximal value of $150 \mu \mathrm{E} \cdot \mathrm{m}^{-2} \cdot \mathrm{s}^{-1}$ to a minimal value of $75 \mu \mathrm{E} \cdot \mathrm{m}^{-2} \cdot \mathrm{s}^{-1}$, the average irradiance being slightly higher when operating at 0.3 day $^{-1}$ that when operating at 0.2 day $^{-1}$ (Figure 3B). In contrast, in the NS oriented PBRs the average irradiance increases when the percentage of centrate increases from 20 to $40 \%$, achieving a maximal value of $320 \mu \mathrm{E} \cdot \mathrm{m}^{-2} \cdot \mathrm{s}^{-1}$, in this case no clear influence of set D being observed. That is more relevant is the dramatic increase of average irradiance when culture medium containing up to $50 \%$ of centrate was used, reaching values up to $776 \mu \mathrm{E} \cdot \mathrm{m}^{-2} \cdot \mathrm{s}^{-1}$. The large average irradiance values existing when using $50 \%$ of centrate into the culture medium clearly shows inadequate culture conditions, the biomass concentration strongly reducing and cells receiving much more light that they can process, then the overall performance of the system being inadequate. Concerning the differences observed between EW and NS oriented PBRs, they can be due to the different light distribution on both systems along the day. Thus, in summer time the EW reactor receive more light than the NS reactor in total amount, but also the light is better distributed along the day being higher in the first and end hours of sunlight period but lower at noon when sunlight is maximal and photoinhibition can take place (Sierra et al., 2008). According to these results the EW 
orientation provides advantages in terms of sunlight capture and distribution, facilitating the efficient use of sunlight by the cells. By comparing the experimental values with that obtained in other systems similar results were obtained. Thus, in light saturated cultures it is expected that the average irradiance remains in the range of half of saturation irradiance for whatever microalgae, then because the minimum values of average irradiance were close to $75 \mu \mathrm{E} \cdot \mathrm{m}^{-}$ ${ }^{2} \cdot \mathrm{s}^{-1}$ it means that the estimated saturation irradiance for Geitlerinema $s p$. must be close to $150 \mu \mathrm{E} \cdot \mathrm{m}^{-2} \cdot \mathrm{s}^{-1}$, analogous to other reported trains as Scenedesmus, Isochrysis g. and T-ISO (Costache et al., 2013; Fernández-Sevilla et al., 1998; Ippoliti et al., 2016). Experimental values of average irradiance were analogous to that reported in raceways with Nannochloropsis $g$. also using centrate as the nutrient source, of $80 \mu \mathrm{E} \cdot \mathrm{m}^{-2} \cdot \mathrm{s}^{-1}$ (Ledda et al., 2015), whereas at indoor conditions with lower irradiance at the reactor surface the average irradiance inside the cultures was $30 \mu \mathrm{E} \cdot \mathrm{m}^{2} \cdot \mathrm{s}^{-1}$, thus indicating that at laboratory conditions the cultures are more photo-limited than outdoors (Sepúlveda et al., 2015). Also for Nannochloropsis $g$. but in outdoor tubular PBRs the average irradiance was up to 124 $\mu \mathrm{E} \cdot \mathrm{m}^{2} \cdot \mathrm{s}^{-1}$ using standard algal medium (San Pedro et al., 2016), thus confirming that FPPBRs are more photo-limited than tubular ones, thus a lower biomass productivity being expected on these systems but in opposite a higher photosynthetic efficiency.

To evaluate the influence of set culture conditions into the efficiency of the cultures the quantum yield (Figure 3C) and photosynthetic efficiency (Figure 3D) were calculated. Quantum yield is related with the amount of biomass produced by photon units available into the culture, then its behaviour being analogous to biomass productivity previously observed. Thus, quantum yield reduces when increasing the percentage of centrate into the culture medium, it being higher at 0.3 day $^{-1} \mathrm{D}$ than at $0.2 \mathrm{day}^{-1}$, no effect of orientation of the PBRs being observed. Maximal value here achieved with Geitlerinema sp., of $0.45 \mathrm{~g}_{\text {biomass }} \cdot \mathrm{E}^{-1}$ is 
analogous to that obtained in Nannochloropsis $g$. cultures also using centrate as nutrients source, of 0.5 g biomass $\mathrm{E}^{-1}$ in tubular PBRs (Romero Villegas et al., 2017), or $0.7 \mathrm{~g}_{\text {biomass }} \cdot \mathrm{E}^{-1}$ and $0.23 \mathrm{~g}_{\text {biomass }} \cdot \mathrm{E}^{-1}$ for tubular and raceway PBRs respectively (Ledda et al., 2015). Using standard culture medium instead of centrate a maximal quantum yield of $0.29 \mathrm{~g}_{\text {biomass }} \cdot \mathrm{E}^{-1}$ has been reported for Nannochloropsis $g$. cultures in outdoor FP-PBRs at 0.35 day $^{-1}$ (San Pedro et al., 2016). Maximal values of $0.6 \mathrm{~g}_{\text {biomass }} \cdot \mathrm{E}^{-1}$ has been reported for outdoor cultures of Scenedesmus sp. in both thin-layer and raceway PBRs, when adding $30 \%$ of centrate the culture medium (Morales-Amaral et al., 2015b). For other strains as Muriellopsis sp. and Pseudokirchneriella s. maximal quantum yields of $0.50 \mathrm{~g} \cdot \mathrm{E}^{-1}$ and $0.43 \mathrm{~g} \cdot \mathrm{E}^{-1}$ were measured when supplying $30 \%$ of centrate to the culture medium at laboratory conditions (MoralesAmaral et al., 2015a), whereas using standard culture medium a maximal value of $0.62 \mathrm{~g} \cdot \mathrm{E}^{-}$ ${ }^{1}$ was reported for Isochrysis $g$. indoors cultures, this value reducing to $0.1 \mathrm{~g} \cdot \mathrm{E}^{-1}$ when the cultures are performed outdoors (Molina-Grima et al., 1997). From these results it could be concluded that quantum yield is mainly a function of used strain and adequacy of culture medium to that required by the selected strains, it being only possible to achieve high quantum yield values when using robust strains tolerant to adverse outdoor conditions and when providing adequate culture medium. The cultures here reported, mainly with Geitlerinema sp., shows to accomplish these requirements. A similar trend that obtained for quantum yield was observed for photosynthetic efficiency measurements, this parameter representing the amount of energy efficiently stored into the produced biomass with respect to that received from the sun. Because whatever the essayed culture conditions the radiation received from the sun was similar, the photosynthetic efficiency was mainly a function of biomass productivity thus the same trend being observed. What is more noticeable is the high values obtained, up to $2.79 \%$ when using $20 \%$ of centrate into the culture medium at a D of 
0.3 day $^{-1}$. This value is lower to reported as theoretical maximum of $10 \%$ of solar energy (photosynthetic efficiency), but outdoor microalgal production systems rarely exceed $6 \%$ as yet (Carvalho et al., 2006; Tredici, 2010). Using 30\% of centrate into the culture medium maximal values of $4.3 \%$ and $1.3 \%$ has been reported for Nannochloropsis g. cultures performed in tubular and raceway PBRs respectively (Ledda et al., 2015), whereas using standard culture medium values up to $1.84 \%$ has been reported also in tubular PBRs with Nannochloropsis g. (San Pedro et al., 2016). The values reported here are close to the maximal values reported for outdoor cultures, $6.94 \%$ to $7.05 \%$ previously reported for Chlorella sp. cultures in thin-layer PBRs (Doucha et al., 2009), or 3.6\% reported for Scenedesmus sp. cultures in large tubular PBRs (Acién et al., 2012).

In addition to the biomass productivity and efficiency into the use of solar energy, the recovery of nutrients from the culture medium and specially the composition of the culture broth exhausting the process is highly relevant. To study the phenomena related with the removal of nutrients the concentration of nitrogen, phosphorus and carbon inlet and outlet the PBRs were determined. Concerning carbon, the total inorganic (TIC) and total organic (TOC) carbon concentrations were measured, the total carbon (TC) being calculated by adding both measurements. Results shows as the total carbon concentration inlet increases when increasing the percentage of centrate into the culture medium, values ranging from 96 $\mathrm{mg} \cdot \mathrm{l}^{-1}$ to $217 \mathrm{mg} \cdot \mathrm{l}^{-1}$, but the total carbon concentration outlet remains lower than $70 \mathrm{mg} \cdot \mathrm{l}^{-1}$ at centrate percentages below 40\%, whatever the set D orientation of the PBRs (Figure 4). Opposite, the total carbon outlet is equal to that inlet when using $50 \%$ of centrate into the culture medium because at these conditions the performance of the cultures was poor and microalgae cells were not able to remove carbon from the culture broth. Analysing the inorganic and organic forms of carbon results shows as inorganic carbon is that mainly 
contributing to total carbon, contribution of organic carbon being poor, lower than $10 \%$ (Figure 4B, C). This is due to the high concentration of bicarbonate in the used centrate, its concentration of organic matter being low, and it being reduced when diluting the centrate with natural seawater to prepare the final culture media used. The low concentration of organic matter also facilitates the maintenance of clean microalgae cultures, reducing the concentration of bacteria. It is also noticeable that organic carbon concentration outlet was including higher than inlet, although always lower than $25 \mathrm{mg} \cdot \mathrm{l}^{-1}$, independently of set culture conditions. These results confirm that the exhausted media accomplish regulation in terms of organic matter. Thus, a linear relationship exists between TOC and COD $(\mathrm{COD}=7.25+2.99 *$ TOC (Dubber and Gray, 2010)), for a total organic carbon concentration of $25 \mathrm{mg} \cdot \mathrm{l}^{-1}$ the estimated COD value is $82 \mathrm{mg} \cdot \mathrm{l}^{-1}$, which is lower than imposed by the European Commission Directive (Directive, 1998) of $100 \mathrm{mg} \cdot \mathrm{l}^{-1}$ equivalent to $31 \mathrm{mg} \cdot \mathrm{l}^{-1} \mathrm{of}$ total organic carbon. Moreover, existing organic matter is not related with that inlet don't being treated but mainly related with the release of compounds by the microalgae cells or cell debris remaining after separation of the microalgae biomass. It has been extensively reported that specially cyanobacteria can release large amounts of polysaccharides and other metabolites to the culture media (Borowitzka, 2013). Concerning inorganic carbon concentration, the experimental values increases from 90 to $220 \mathrm{mg} \cdot \mathrm{l}^{-1}$ when increasing the percentage of centrate from 20 to $50 \%$ (Fig. 4B). Considering that $50 \%$ of the microalgae biomass is carbon the maximum amount of biomass possible to be produced according to the inorganic carbon availability ranged from 180 to $440 \mathrm{mg} \cdot \mathrm{l}^{-1}$. However, including if this amount of biomass to be produced per unit of culture medium is acceptable the major problem is the large variation of $\mathrm{pH}$ that take place into the cultures when depleting the bicarbonate buffer, it strongly reducing the performance of the cultures, whatever the strain 
or photobioreactor used. By these raisons the supply of $\mathrm{CO}_{2}$ as additional carbon source and to control the $\mathrm{pH}$ is mandatory in microalgae cultures if high biomass productivity is pursued (Posadas et al., 2015). Despite relatively high concentration of inorganic carbon in the inlet, at the outlet the inorganic carbon concentration was always low, with maximal values of 90 $\mathrm{mg} \cdot \mathrm{l}^{-1}$, analogous to that found in natural seawater or freshwater sources, so exhausted culture broth being acceptable for safe releasing to environment. It has been reported that using wastewater the organic carbon contained on these effluents can enhance the productivity of microalgae cultures by favouring mixotrophic and including heterotrophic growth (Alam et al., 2015). However, based on the values here reported this fact don't take place when using centrate as nutrients source including at high percentages at which the cultures are stressed by excess of ammonium.

Regarding nitrogen (Figure 5A) and phosphorus (Figure 5B), an equivalent analysis was performed. Nitrogen concentration inlet increases with the percentage of centrate into the culture medium from 113 to $288 \mathrm{mg}_{\mathrm{N}} \cdot \mathrm{l}^{-1}$, it being mainly $(85 \%)$ in the form of ammonium instead nitrate or other organic forms. At the outlet the nitrogen concentration increases from 17 to $102 \mathrm{mg} \cdot \mathrm{l}^{-1}$ when the centrate percentage increases from $20 \%$ to $50 \%$ no large influence of D or orientation of the PBRs being observed. These results indicate that the cultures were not capable to completely remove the nitrogen provided to the systems, including when using only $20 \%$ of nitrogen into the culture medium. This can be due to that the amount of nitrogen provided overpasses the capacity of the system (strain + PBRs + culture conditions) or due to whatever adverse effect reducing the maximum capacity of the system. It must be noticed that although the ammonium concentration inlet largely exceed the limit value reported of $100 \mathrm{mg} \cdot \mathrm{l}^{-1}$ (Collos and Harrison, 2014), because the PBRs were operated in semicontinuous mode the real ammonium concentration measured into the cultures was always lower than 
this limit when using percentages of centrate up to $40 \%$, only achieving the limit of $100 \mathrm{mg} \cdot \mathrm{l}^{-}$ ${ }^{1}$ when using $50 \%$ of centrate into the culture medium. This fact explains the adverse performance of experiments performed providing $50 \%$ of centrate to the culture medium, but also that cultures can be stressed in the $4 \mathrm{~h}$ period on which the culture medium is supplied, and peaks of ammonium concentration can be achieved into the culture including when using only 30 or $40 \%$ of centrate into the culture medium. Anyway, the major problem is that according to these figures the exhausted culture don't accomplish the requirements of the European Commission Directive 98/15/EEC for the disposal in sensitive areas $\left(10 \mathrm{mg} \cdot \mathrm{l}^{-1}\right)$ (Directive, 1998). To accomplish this regulation, the culture conditions must be modified by reducing the amount of nitrogen inlet by reducing the percentage of centrate below $20 \%$.

In the case of phosphorous a similar trend that observed for nitrogen was observed (Figure 5B). It must to be noticed that additional phosphorous was added to the culture medium to maintain a $\mathrm{N}: \mathrm{P}$ ratio of 5, thus avoiding $\mathrm{P}$ limitation for the removal of $\mathrm{N}$ and allowing to maximize the performance of the microalgae cells and to remove $\mathrm{N}$ contained into the culture medium (Sepúlveda et al., 2015). It has been reported that the imbalanced N:P ratio influences not only nitrogen removal but also biomass production (Wang et al., 2010b). Results shows as the phosphorous concentration inlet increases with $16 \mathrm{mg} \cdot \mathrm{l}^{-1}$ to $46 \mathrm{mg} \cdot \mathrm{l}^{-1}$ when increasing the percentage of centrate from 20 to $50 \%$, whereas at the outlet phosphorous concentration ranged from $0.1 \mathrm{mg} \cdot \mathrm{l}^{-1}$ to $20 \mathrm{mg} \cdot \mathrm{l}^{-1}$ at the same conditions. Equal than for nitrogen the increase on phosphorous concentration outlet indicates that the capacity of system is overpassed or whatever negative effect is limiting the phosphorous removal capacity, excess of ammonium being the probably adverse effect. Anyway, the good news is that when operating at 0.2 day $^{-1} \mathrm{D}$ and using $20 \%$ of centrate the phosphorous concentration 
outlet, whatever the orientation of the reactor, is lower than $1 \mathrm{mg} \cdot \mathrm{l}^{-1}$ thus accomplishing European regulation for disposal of water in sensitive areas (Directive, 1998).

In addition to nutrients concentrations inlet and outlet, which are highly relevant especially in terms of regulations, it is interesting to evaluate the performance of the system is terms of removal capacity and efficiency, thus analysing the influence of culture conditions into the performance of the system. Results shows as both the total carbon removal efficiency and capacity increases when the percentage of centrate into the culture medium increases up to $40 \%$, no large influence of set D or orientation of the PBRs being observed (Figure 6A). Experimental values ranged from $30 \%$ to $80 \%$ in terms of efficiency, and from $10 \mathrm{mg} \cdot{ }^{-1} \cdot$ day $^{-}$ ${ }^{1}$ to $50 \mathrm{mg} \cdot \mathrm{l}^{-1} \cdot$ day $^{-1}$ in terms of removal capacity. Only when using $50 \%$ of centrate into the culture medium both the total carbon removal efficiency and capacity greatly reduced by inadequate performance of the cultures. Regarding nitrogen, an opposite variation was observed (Figure 6B). Thus, the removal efficiency reduces when the percentage of centrate into the culture medium increases but the removal capacity increases at the same conditions. Experimental values ranged from $85 \%$ to $65 \%$, and from $20 \mathrm{mg} \cdot \mathrm{l}^{-1} \cdot \mathrm{day}^{-1}$ to $70 \mathrm{mg} \cdot \mathrm{l}^{-1} \cdot \mathrm{day}^{-1}$ for both nitrogen removal efficiency and capacity respectively. The set D had also a relevant influence in the nitrogen removal capacity, it being higher at $0.3 \mathrm{day}^{-1}$ that at $0.2 \mathrm{day}^{-1}$, no influence of orientation of the PBRs being observed. These results confirm that nitrogen removal is linked with biomass production, so it being higher when optimal D is set, but not only because nitrogen removal capacity increases with the increase of centrate percentage into the culture medium but is was previously observed that at these conditions the biomass productivity reduces. Moreover, including when using $50 \%$ of centrate into the culture medium a high nitrogen removal capacity was measured but at these conditions excess of ammonium reduces the performance of the cultures, so the biomass productivity was the 
lowest. The raisons for these results is that other phenomena than biological also take places as nitrogen stripping, which is enhanced the higher the ammonium concentration into the culture medium, so the percentage of centrate provided. Regarding phosphorus, results shows as increasing the percentage of centrate into the culture medium the removal efficiency reduces whereas the removal capacity increases capacity, below $40 \%$ of centrate into the culture medium (Figure 6C). When supplying 50\% of centrate the cultures were stressed, and the removal efficiency and capacity greatly reduces. In the range of 20 to $40 \%$ the removal efficiency and capacity ranges from $94 \%$ to $64 \%$, and from $3.8 \mathrm{mg} \cdot 1^{-1} \cdot$ day $^{-1}$ to $9.4 \mathrm{mg} \cdot l^{-1} \cdot$ day $^{-}$ ${ }^{1}$, respectively. Full efficiency (100\%) of phosphorous removal was only achieved with $20 \%$ centrate and at 0.2 day $^{-1}$. Analogous to nitrogen the phosphorous removal capacity was higher when operating at 0.3 day $^{-1}$ than at 0.2 day $^{-1} \mathrm{D}$. These results also show a link between biomass productivity and phosphorous removal, but this relationship is not linear, other phenomena than biological ones taking place as phosphorous precipitation when high phosphorous concentrations and alkaline $\mathrm{pH}$ exists in the presence of elements as calcium, etc.

The coupling between microalgae production and wastewater treatment has been widely reported, concluding that it is not possible to provide an unique single process to perform this coupling, the right design and operation conditions being a function of water composition, prevailing conditions and biology of the system used (Acién et al., 2016; Craggs et al., 2012; Muñoz et al., 2009). Whatever the scheme finally used to determine the nutrients removal efficiency and capacity is mandatory to adequately manage the system. Using centrate as nutrients source Nannochloropsis g. cultures were able to remove up to $100 \%$ of nitrogen and $80 \%$ of phosphorous in light limited cultures at laboratory scale (Sepúlveda et al., 2015). Using the same strain and centrate, the removal efficiency was up to $0.14 \mathrm{~g} \cdot \mathrm{m}^{-2} \cdot \mathrm{day}^{-1}$ and 
$0.16 \mathrm{~g} \cdot \mathrm{m}^{-2} \cdot$ day $^{-1}$ when using tubular and raceway PBRs (Ledda et al., 2015). Greatly varying nutrient removal efficiencies have been reported based on the strain and nutrient source used. When using $30 \%$ centrate in the culture medium, the nitrogen removal efficiency in thinlayer and raceway PBRs with Scenedesmus sp. was 96\% and 55\% respectively; while the phosphorus removal efficiency was 50\% and 10\%, respectively (Morales-Amaral et al., 2015b). Using Chlorella v. and centrate, removal efficiencies of $11 \%$ and $45 \%$ were reported for nitrogen and phosphorus, respectively (Min et al., 2012). Using anaerobic digestate from dairy manure, the ammonium was completely removed with Chlorella v. (Wang et al., 2010a), whereas using Neochloris oleoabundans, the ammonium removal rate was 90-95\% (Yang et al., 2011). Phosphorus is essential for algal growth as it is involved in many cellular processes even though it makes up less than $1 \%$ of the biomass. A phosphorus removal efficiency of between $63 \%$ and $75 \%$ was previously reported with Chlorella sp. with anaerobic digestate from dairy manure (Wang et al., 2010a), while phosphorus removal from urban wastewater was $80 \%$ for Chlorella sp. and $83 \%$ for Scenedesmus obliquus (Ruiz-Marin et al., 2010).

To better understand the major factors limiting the nutrients removal mass balances were applied to identify the main phenomena taking place. Thus, nutrients inlet with the culture medium, outlet with the culture broth and that accumulated into the biomass were determined. Results shows as carbon was mainly fixed as biomass, from 76 to $85 \%$, the carbon remaining into the supernatant being the second major contribution, it ranging from 7 to $18 \%$, whereas the carbon losses to the atmosphere were really low, from 5 to $8 \%$ (Figure 7A). These values were that obtained when using percentages of centrate into the culture medium ranging from 20 to $40 \%$, on which the performance of the cultures was adequate. 
When $50 \%$ of centrate was provided to the culture medium the performance of the cultures was not adequate then the results greatly modified, thus only $14 \%$ of the inlet carbon being assimilated by the biomass, up to $82 \%$ remaining into the culture broth and only $4 \%$ being lost to the atmosphere. These results confirm that decarbonisation is almost depreciable at these conditions, the main phenomena taking place being the assimilation by the cells or accumulation into the culture medium. No influence of the set D or orientation of the PBRs was observed. These results are similar to those obtained in tubular PBRs with Nannochloropsis $g$. also using centrate as nutrients source, where up to $80 \%$ of carbon was fixed into the biomass (Romero Villegas et al., 2017), and confirm that at the essayed conditions the cultures were carbon limited this limitation being avoided by the on-demand supply of $\mathrm{CO}_{2}$ for $\mathrm{pH}$ control.

Regarding nitrogen results shows as the percentage of nitrogen efficiently assimilated by the biomass reduces from 60 to $15 \%$ when increasing the percentage of centrate into the culture medium from 20 to $40 \%$, whatever the set D and orientation of the reactor (Figure 7B). When providing $50 \%$ of centrate into the culture medium the cultures were strongly stressed, and the percentage of nitrogen inlet finally assimilated into the biomass was negligible. The percentage of nitrogen inlet remaining into the cultures was almost constant whatever the percentage of centrate, D and orientation of the PBRs, whereas the stripping of ammonium also showing a high correlation with the percentage of centrate into the culture medium inlet. Thus, when increasing the percentage of centrate into the culture medium from 20 to $40 \%$ the losses of nitrogen by stripping increase from 26 to $62 \%$. These results confirm that including at $20 \%$ of centrate into the culture medium the capacity of the system to remove nitrogen was overpassed, this oversaturation being enhanced when increasing the percentage of centrate. The excess of nitrogen provided was accumulated into the culture broth but 
because it was in equilibrium with bubble air a large proportion of nitrogen was stripped, the only remaining that in equilibrium with the air at the set conditions. The amount of nitrogen that can be removed by the cells is a direct function of biomass productivity, thus because the biomass productivity decreases when the percentage of centrate was higher than $20 \%$, also the nitrogen losses by stripping increases at these conditions. This behaviour has previously been reported, where high $\mathrm{pH}$ and temperature enhance ammonia stripping (Posadas et al., 2015; Ruiz-Marin et al., 2010). The relevance of nitrogen stripping in aerated wastewater treatment processes has been widely reported, it being especially relevant when at aeration rates higher than $0.15 \mathrm{v} \cdot \mathrm{v}^{-1} \cdot \mathrm{min}^{-1}$ and $\mathrm{pH}$ upper than 7.0 (Guštin and MarinšekLogar, 2011). In raceway PBRs it has been reported that nitrogen losses by stripping increases from 45 to $65 \%$ when increasing the percentage of centrate into the culture medium from 30 to $60 \%$ using Scenedesmus sp., whereas at the same conditions the nitrogen losses by stripping increases from zero to $15 \%$ when using thin-layer PBRs (Morales-Amaral et al., 2015b). Because in thin-layer PBRs higher biomass productivities were achieved the concentration of ammonium remaining into the culture broth reduces, also the losses by stripping reducing, thus confirming the relevance of increasing the biomass productivity to enhance the removal efficiency or capacity of the systems. The removal of nitrogen by stripping was also favoured by the no existence of nitrification phenomena, thus the nitrate concentration into the culture being negligible whatever the experimental conditions essayed. In the case of phosphorous a similar trend that analysed for nitrogen was observed. Thus, the percentage of phosphorous inlet assimilated by the biomass reduces from 54 to $12 \%$ when the percentage of centrate into the culture medium increases from 20 to $40 \%$, whatever the set $\mathrm{D}$ and orientation of the reactor, it being negligible when using $50 \%$ of centrate into the culture medium (Figure 7C). Opposite, the percentage of phosphorous inlet remaining into 
the culture broth increases from 5 to $40 \%$ when increasing the percentage of centrate into the culture medium from 20 to $40 \%$, and up to $60 \%$ when providing $50 \%$ of centrate into the culture medium. Phosphorous losses can be related with that precipitated into the reactor, it ranges from 20 to $50 \%$ when increasing the percentage into the culture medium up to $40 \%$, and up to $60 \%$ when supplying $50 \%$ of centrate. These results confirm that the removal of phosphorus is related with the production of biomass, equal that the nitrogen removal, thus it is reducing when the percentage of centrate into the culture medium increases by reduction of biomass productivity at these conditions but also by the excess of phosphorous supply. It is also noticeable that phosphorous losses by precipitation are highly relevant, but it only takes place when excess of phosphorus not consumed by the cells remains into the supernatant. Precipitation of phosphorous has been previously reported to be highly relevant at high carbonate content in the culture medium and pH above 7.5 (Burns et al., 2003).

To conclude the analysis of the system the composition/quality of produced biomass was determined. Results shows as carbohydrates and proteins are the major components of the biomass, the lipids content being much lower (Figure 8). The carbohydrates content increases from 20 to $50 \%$ d.wt. when increasing the percentage of centrate into the culture medium from 20 to $40 \%$, a clear effect of set D or orientation of the PBRs being observed. In the case of proteins, the experimental values ranged from 15 to $35 \%$ d.wt., a clear effect of modified variables being not observed. Regarding lipids, the content modifies from 27 to 5\%d.wt., it reducing when increasing the percentage of centrate into the culture medium or increasing the set D, no effect of orientation of the reactor being observed. According to these results the biochemical composition of the biomass can be manipulated mainly by increasing the percentage of centrate into the culture medium then increasing the percentage of carbohydrates and reducing the percentage of lipids contained into the biomass whereas the 
protein content remains constant. Alternatively, it can be manipulated by modifying the set $\mathrm{D}$, thus the higher $\mathrm{D}$ the lower is the lipids content opposite the carbohydrates content slightly increasing. However, the maximal biomass productivity was obtained at the minimum percentage of centrate and the higher D essayed, whatever the orientation of the PBRs, then at these conditions the biomass containing $22 \%$ d.wt. of carbohydrates, $35 \%$ d.wt. of proteins and $16 \%$ d.wt. of lipids in addition to ashes. Since it has been estimated that the microalgal biomass selling price is $>5.0 € \cdot \mathrm{kg}_{\text {Dryweight }}{ }^{-1}$ using mineral fertilizer and fresh water. Nevertheless, the use of wastewater and flue gases could reduce the production cost below $0.5 € \cdot \mathrm{kg}_{\text {Dryweight }}{ }^{-1}$ (Acién et al., 2013). Furthermore, the approximate market price for proteins, lipids and carbohydrates are $1.0 € \cdot \mathrm{kg}^{-1}, 0.6 € \cdot \mathrm{kg}^{-1}$ and $0.3 € \cdot \mathrm{kg}^{-1}$ respectively (Ruiz et al., 2016), Thus it has been calculated that the value of produced biomass in this study is around $0.59 € \cdot \mathrm{kg}^{-1}$. Based on these results it can be concluded that to achieve economic profitability it is necessary to develop cheap production processes, able to produce biomass at production costs below this value, whereas because the biomass is produced using wastes it must be used to produce animal feed or biofertilizers. The biochemical composition determined at optimal conditions, especially the high proteins content, allows to be optimistic about the potential use of the biomass to produce biofertilizers or animal feed including for aquaculture.

\section{Conclusions}

It has been demonstrated that marine microalgae can be produced in FP-PBRs using centrate as nutrients source, under not sterile conditions the prevailing strain being Geitlerinema sp. Optimal performance of the system was achieved when using $20 \%$ of centrate into the culture medium, upper than this value the nutrients inlet overpassing the capacity of the cells to remove the supplied nutrients. No influence of orientation of the PBRs EW or NS was 
observed, the optimal performance being obtained at 0.3 day $^{-1} \mathrm{D}$. The biomass produced was enough cheap and useful for producing biofertilizers and animal feed.

\section{Acknowledgements}

This research was supported by the EDARSOL Project (CTQ2014-57293-C3) financed by the Spanish Government and Junta de Andalucia (BIO 173), European Commission through the ERANET LAC Program by GreenBiorefinery project (ELAC2014/BEE-0357), and the European Union's Horizon 2020 Research and Innovation Program under Grant Agreement No. 727874 SABANA. Gabriel Ivan Romero Villegas and Marco Fiamengo contributions were financially supported by the Mexican National Council on Science and Technology (CONACyT) and by the Erasmus+ traineeship program of the Università di Ferrara.

\section{References}

Acién, F.G., Fernández, J.M., Magán, J.J., Molina, E., 2012. Production cost of a real microalgae production plant and strategies to reduce it. Biotechnol. Adv. 30, 13441353. https://doi.org/10.1016/j.biotechadv.2012.02.005

Acién, F.G., Fernández, J.M., Molina-Grima, E., 2013. Economics of Microalgae Biomass Production, in: Biofuels from Algae. pp. 313-325. https://doi.org/10.1016/B978-0444-59558-4.00014-0

Acién, F.G., Gómez-Serrano, C., Morales-Amaral, M.M., Fernández-Sevilla, J.M., MolinaGrima, E., 2016. Wastewater treatment using microalgae: how realistic a contribution might it be to significant urban wastewater treatment? Appl. Microbiol. Biotechnol. 100, 9013-9022. https://doi.org/10.1007/s00253-016-7835-7

Acién Fernández, F.G., Fernández Sevilla, J.M., Molina Grima, E., 2013. Photobioreactors for the production of microalgae. Rev. Environ. Sci. Biotechnol. 12, 131-151. https://doi.org/10.1007/s11157-012-9307-6

Alam, A., Ullah, S., Alam, S., Shah, H.U., Aftab, S., Siddiq, M., Manzoor, N., 2015. Influence of culture media and carbon sources on biomass productivity and oil content 
of the algae Sirogonium sticticum, Temnogyra reflexa, Uronema elongatum, and Chroococcus turgidus. Turk. J. Botany 39, 599-605. https://doi.org/10.3906/bot-140516

Andrianasolo, E.H., Gross, H., Goeger, D., Musafija-Girt, M., McPhail, K., Leal, R.M., Mooberry, S.L., Gerwick, W.H., 2005. Isolation of swinholide A and related glycosylated derivatives from two field collections of marine cyanobacteria. Org. Lett. 7, 1375-1378. https://doi.org/10.1021/ol050188x

Borowitzka, M.A., 2013. High-value products from microalgae - their development and commercialisation. J. Appl. Phycol. 25, 743-756. https://doi.org/10.1007/s10811-0139983-9

Burns, R.T., Moody, L.B., Celen, I., Buchanan, J.R., 2003. Optimization of phosphorus precipitation from swine manure slurries to enhance recovery, in: Water Science and Technology. pp. 139-146.

Caporgno, M.P., Trobajo, R., Caiola, N., Ibáñez, C., Fabregat, A., Bengoa, C., 2015. Biogas production from sewage sludge and microalgae co-digestion under mesophilic and thermophilic conditions. Renew. Energy 75, 374-380.

https://doi.org/10.1016/j.renene.2014.10.019

Carvalho, A.P., Meireles, L.A., Malcata, F.X., 2006. Microalgal reactors: A review of enclosed system designs and performances. Biotechnol. Prog. https://doi.org/10.1021/bp060065r

Collos, Y., Harrison, P.J., 2014. Acclimation and toxicity of high ammonium concentrations to unicellular algae. Mar. Pollut. Bull. 80, 8-23. https://doi.org/10.1016/j.marpolbul.2014.01.006

Costache, T.A.A., Fernández, F.G.A., Acien, F.G., Morales, M.M., Fernández-Sevilla, J.M., Stamatin, I., Molina, E., 2013. Comprehensive model of microalgae photosynthesis rate as a function of culture conditions in photobioreactors. Appl. Microbiol. Biotechnol. 97, 7627-7637. https://doi.org/10.1007/s00253-013-5035-2

Craggs, R., Sutherland, D., Campbell, H., 2012. Hectare-scale demonstration of high rate algal ponds for enhanced wastewater treatment and biofuel production. J. Appl. Phycol. 24, 329-337.

Directive, E.C., 1998. 98/15/EC of 27 February. 
Doucha, J., Lívanský, K., Lívanský, K., 2009. Outdoor open thin-layer microalgal photobioreactor: Potential productivity. J. Appl. Phycol. 21, 111-117. https://doi.org/10.1007/s10811-008-9336-2

Dubber, D., Gray, N.F., 2010. Replacement of chemical oxygen demand (COD) with total organic carbon (TOC) for monitoring wastewater treatment performance to minimize disposal of toxic analytical waste. J. Environ. Sci. Heal. Part A 45, 1595-1600. https://doi.org/10.1080/10934529.2010.506116

Fernández-Sevilla, J.M., Molina-Grima, E., García-Camacho, F., Acién, F.G., SánchezPérez, J.A., 1998. Photolimitation and photoinhibition as factors determining optimal dilution rate to produce eicosapentaenoic acid from cultures of the microalga Isochrysis galbana. Appl. Microbiol. Biotechnol. 50, 199-205. https://doi.org/10.1007/s002530051277

Ferrero, E.M., de Godos, I., Rodríguez, E.M., García-Encina, P.A., Muñoz, R., Bécares, E., 2012. Molecular characterization of bacterial communities in algal-bacterial photobioreactors treating piggery wastewaters. Ecol. Eng. 40, 121-130. https://doi.org/10.1016/j.ecoleng.2011.10.001

Guštin, S., Marinšek-Logar, R., 2011. Effect of pH, temperature and air flow rate on the continuous ammonia stripping of the anaerobic digestion effluent. Process Saf. Environ. Prot. 89, 61-66. https://doi.org/10.1016/j.psep.2010.11.001

Hašler, P., Dvořák, P., Johansen, J.R., Kitner, M., Ondřej, V., Poulíčková, A., 2012. Morphological and molecular study of epipelic filamentous genera Phormidium, Microcoleus and Geitlerinema (Oscillatoriales, Cyanophyta/ cyanobacteria). Fottea 12, 341-356. https://doi.org/10.5507/fot.2012.024

Ippoliti, D., Gómez, C., Morales-Amaral, M.M., Pistocchi, R., Fernández-Sevilla, J.M.M., Acién, F.G.G., del Mar Morales-Amaral, M., Pistocchi, R., Fernández-Sevilla, J.M.M., Acién, F.G.G., 2016. Modeling of photosynthesis and respiration rate for Isochrysis galbana (T-Iso) and its influence on the production of this strain. Bioresour. Technol. 203, 71-79. https://doi.org/10.1016/j.biortech.2015.12.050

Jodlowska, S., Latala, A., 2013. Combined effects of light and temperature on growth, photosynthesis, and pigment content in the mat-forming cyanobacterium Geitlerinema amphibium. Photosynthetica 51, 202-214. https://doi.org/10.1007/s11099-013-0019-0 
Latala, A., Misiewicz, S., 2000. Effects of light, temperature and salinity on the growth and chlorophyll a content of Baltic cyanobacterium Phormidium amphibium. Algol. Stud. für Hydrobiol. Suppl. Vol. 100, 157-180.

Ledda, C., Romero-Villegas, G.I., Adani, F., Acién-Fernández, F.G., Molina-Grima, E., 2015. Utilization of centrate from wastewater treatment for the outdoor production of Nannochloropsis gaditana biomass at pilot-scale. Algal Res. 12. https://doi.org/10.1016/j.algal.2015.08.002

Ledda, C., Schievano, A., Scaglia, B., Rossoni, M., Acién Fernández, F.G., Adani, F., 2016. Integration of microalgae production with anaerobic digestion of dairy cattle manure: An overall mass and energy balance of the process. J. Clean. Prod. 112, 103112. https://doi.org/10.1016/j.jclepro.2015.07.151

Min, M., Hu, B., Zhou, W., Li, Y., Chen, P., Ruan, R., 2012. Mutual influence of light and $\mathrm{CO} 2$ on carbon sequestration via cultivating mixotrophic alga Auxenochlorella protothecoides UMN280 in an organic carbon-rich wastewater. J. Appl. Phycol. 24, 1099-1105. https://doi.org/10.1007/s10811-011-9739-3

Molina-Grima, E., García-Camacho, F., Sánchez-Pérez, J.A., Acién-Fernéndez, F.G., Fernández-Sevilla, J.M., 1997. Evaluation of photosynthetic efficiency in microalgal cultures using averaged irradiance. Enzyme Microb. Technol. 21, 375-381. https://doi.org/10.1016/S0141-0229(97)00012-4

Molina-Grima, E., García-Camacho, F., Sánchez-Pérez, J.A., Fernández-Sevilla, J.M., Acién, F.G., Contreras-Gómez, A., 1994. A mathematical model of microalgal growth in light-limited chemostat culture. J. Chem. Technol. Biotechnol. 61, 167-173. https://doi.org/10.1002/jctb.280610212

Morales-Amaral, M. del M., Gómez-Serrano, C., Acién, F.G., Fernández-Sevilla, J.M., Molina-Grima, E., 2015a. Production of microalgae using centrate from anaerobic digestion as the nutrient source. Algal Res. 9, 297-305. https://doi.org/10.1016/j.algal.2015.03.018

Morales-Amaral, M. del M., Gómez-Serrano, C., Acién, F.G., Fernéndez-Sevilla, J.M., Molina-Grima, E., 2015b. Outdoor production of Scenedesmus sp. in thin-layer and raceway reactors using centrate from anaerobic digestion as the sole nutrient source. Algal Res. 12, 99-108. https://doi.org/10.1016/j.algal.2015.08.020 
Muñoz, R., Köllner, C., Guieysse, B., 2009. Biofilm photobioreactors for the treatment of industrial wastewaters. J. Hazard. Mater. 161, 29-34.

Norsker, N.H., Barbosa, M.J., Vermuë, M.H., Wijffels, R.H., 2011. Microalgal production A close look at the economics. Biotechnol. Adv. https://doi.org/10.1016/j.biotechadv.2010.08.005

Pelczar, M.J., Chan, E.C.., Krieg, N.R., 1993. Microbiology. 5th ed. Tata Mc Graw Hill Publ.

Pires, J.C.M., Alvim-Ferraz, M.C.M., Martins, F.G., Simões, M., 2012. Carbon dioxide capture from flue gases using microalgae: Engineering aspects and biorefinery concept. Renew. Sustain. Energy Rev. https://doi.org/10.1016/j.rser.2012.02.055

Posadas, E., del Mar Morales, M., Gomez, C., Acién, F.G., Muñoz, R., 2015. Influence of $\mathrm{pH}$ and $\mathrm{CO} 2$ source on the performance of microalgae-based secondary domestic wastewater treatment in outdoors pilot raceways. Chem. Eng. J. 265, 239-248.

Richmond, A., Cheng-Wu, Z., 2001. Optimization of a flat plate glass reactor for mass production of Nannochloropsis sp. outdoors. J. Biotechnol. 85, 259-269.

Rodolfi, L., Zittelli, G.C., Bassi, N., Padovani, G., Biondi, N., Bonini, G., Tredici, M.R., 2009. Microalgae for oil: Strain selection, induction of lipid synthesis and outdoor mass cultivation in a low-cost photobioreactor. Biotechnol. Bioeng. 102, 100-112. https://doi.org/10.1002/bit.22033

Romero Villegas, G.I., Fiamengo, M., Acien-Fernández, F.G., Molina-Grima, E., 2017. Outdoor production of microalgae biomass at pilot-scale in seawater using centrate as the nutrient source. Algal Res. 25, 1-11. https://doi.org/10.1016/j.algal.2017.06.016

Ruiz-Marin, A., Mendoza-Espinosa, L.G., Stephenson, T., 2010. Growth and nutrient removal in free and immobilized green algae in batch and semi-continuous cultures treating real wastewater. Bioresour. Technol. 101, 58-64. https://doi.org/10.1016/j.biortech.2009.02.076

Ruiz, J., Olivieri, G., de Vree, J., Bosma, R., Willems, P., Reith, J.H., Eppink, M.H.M., Kleinegris, D.M.M., Wijffels, R.H., Barbosa, M.J., 2016. Towards industrial products from microalgae. Energy Environ. Sci. 24, 405-413. https://doi.org/10.1039/C6EE01493C

San Pedro, A., González-López, C.V., Acién, F.G., Molina-Grima, E., 2016. Outdoor pilot 
production of Nannochloropsis gaditana: Influence of culture parameters and lipid production rates in flat-panel photobioreactors. Algal Res. 18, 156-165.

https://doi.org/10.1016/j.algal.2016.06.011

San Pedro, A., González-López, C.V., Acién, F.G., Molina-Grima, E., 2014. Outdoor pilotscale production of Nannochloropsis gaditana: Influence of culture parameters and lipid production rates in tubular photobioreactors. Bioresour. Technol. 169, 667-676. https://doi.org/10.1016/j.biortech.2014.07.052

Sepúlveda, C., Acién, F.G., Gómez, C., Jiménez-Ruíz, N., Riquelme, C., Molina-Grima, E., 2015. Utilization of centrate for the production of the marine microalgae Nannochloropsis gaditana. Algal Res. 9, 107-116. https://doi.org/10.1016/j.algal.2015.03.004

Sierra, E., Acién, F.G., Fernández, J.M., García, J.L., González, C., Molina, E., 2008. Characterization of a flat plate photobioreactor for the production of microalgae. Chem. Eng. J. 138, 136-147. https://doi.org/10.1016/j.cej.2007.06.004

Silva, S.M.F., Pienaar, R.N., 2000. Some benthic marine Cyanophyceae of Mauritius. Bot. Mar. 43, 11-27.

Tredici, M.R., 2010. Photobiology of microalgae mass cultures: Understanding the tools for the next green revolution. Biofuels 1, 143-162.

Tredici, M.R., Bassi, N., Prussi, M., Biondi, N., Rodolfi, L., Chini Zittelli, G., Sampietro, G., 2015. Energy balance of algal biomass production in a 1-ha "Green Wall Panel" plant: How to produce algal biomass in a closed reactor achieving a high Net Energy Ratio. Appl. Energy 154, 1103-1111. https://doi.org/10.1016/j.apenergy.2015.01.086

Wang, L., Li, Y., Chen, P., Min, M., Chen, Y., Zhu, J., Ruan, R.R., 2010a. Anaerobic digested dairy manure as a nutrient supplement for cultivation of oil-rich green microalgae Chlorella sp. Bioresour. Technol. 101, 2623-2628. https://doi.org/10.1016/j.biortech.2009.10.062

Wang, L., Min, M., Li, Y., Chen, P., Chen, Y., Liu, Y., Wang, Y., Ruan, R., 2010 b. Cultivation of green algae Chlorella sp. in different wastewaters from municipal wastewater treatment plant. Appl. Biochem. Biotechnol. 162, 1174-1186.

Yang, J., Xu, M., Zhang, X., Hu, Q., Sommerfeld, M., Chen, Y., 2011. Corrigendum to "Life-cycle analysis on biodiesel production from microalgae: Water footprint and 
nutrients balance.” Bioresour. Technol. 102, 6633.

Zhou, W., Wang, J., Chen, P., Ji, C., Kang, Q., Lu, B., Li, K., Liu, J., Ruan, R., 2017. Bio-

mitigation of carbon dioxide using microalgal systems: Advances and perspectives. Renew. Sustain. Energy Rev. 76, 1163-1175.

https://doi.org/10.1016/j.rser.2017.03.065

\section{Figure captions}

Figure 1.- Influence of the centrate percentage in the culture medium and the set dilution rate on biomass concentration and productivity in outdoor plastic-bag FP-PBRs. A) Biomass concentration, B) Volumetric biomass productivity, C) Land area biomass productivity. Mean values + S.D. of independent experiments performed in triplicate are shown $(\mathrm{P}<0.05)$.

Figure 2.- Variation in the relative population of microalgae strains in the cultures with (A) the centrate percentage in the culture medium and the set dilution rate $(B)$ in outdoor plasticbag FP-PBRs. Mean values + S.D. of independent experiments performed in triplicate are shown $(\mathrm{P}<0.05)$.

Figure 3.- Influence of the centrate percentage in the culture medium and the set dilution rate on the extinction coefficient of the biomass, the average irradiance inside the culture, the quantum yield and the photosynthetic efficiency in outdoor plastic-bag FP-PBRs. A) Extinction coefficient of the biomass, B) Average irradiance to which the cells are exposed inside the cultures, C) Quantum yield, D) Photosynthetic efficiency. Mean values +S.D. of independent experiments performed in triplicate are shown $(\mathrm{P}<0.05)$.

Figure 4.- Influence of the centrate percentage in the culture medium and the set dilution rate on the total carbon (organic and inorganic) concentration at the inlet and outlet in outdoor plastic-bag FP-PBRs. A) Total Carbon, B) Total Inorganic Carbon, C) Total Organic Carbon. Mean values + S.D. of independent experiments performed in triplicate are shown $(\mathrm{P}<0.05)$.

Figure 5.- Influence of the centrate percentage in the culture medium and the set dilution rate on the nitrogen inlet and outlet concentration, and phosphorus inlet and outlet concentration 
in outdoor plastic-bag FP-PBRs. A) Total nitrogen, B) Total phosphorus. Mean values +S.D. of independent experiments performed in triplicate are shown $(\mathrm{P}<0.05)$.

Figure 6.- Influence of the centrate percentage in the culture medium and the set dilution rate on the carbon, nitrogen and phosphorus removal efficiency and capacity in outdoor plasticbag FP-PBRs. A) Total carbon, B) Total nitrogen, C) Total phosphorus. Mean values +S.D. of independent experiments performed in triplicate are shown $(\mathrm{P}<0.05)$.

Figure 7.- Influence of the centrate percentage in the culture medium and the set dilution rate on the carbon, nitrogen and phosphorus mass balance of the system in outdoor plastic-bag FP-PBRs. A) Carbon, B) Nitrogen, C) Phosphorus. Mean values +S.D. of independent experiments performed in triplicate are shown $(\mathrm{P}<0.05)$.

Figure 8.- Variation in the (A) carbohydrate content, (B) protein content and (C) lipid content of the microalgae biomass produced as a function of the centrate percentage in the culture medium and the set dilution rate in outdoor plastic-bag FP-PBRs. Mean values +S.D. of independent experiments performed in triplicate are shown $(\mathrm{P}<0.05)$. 

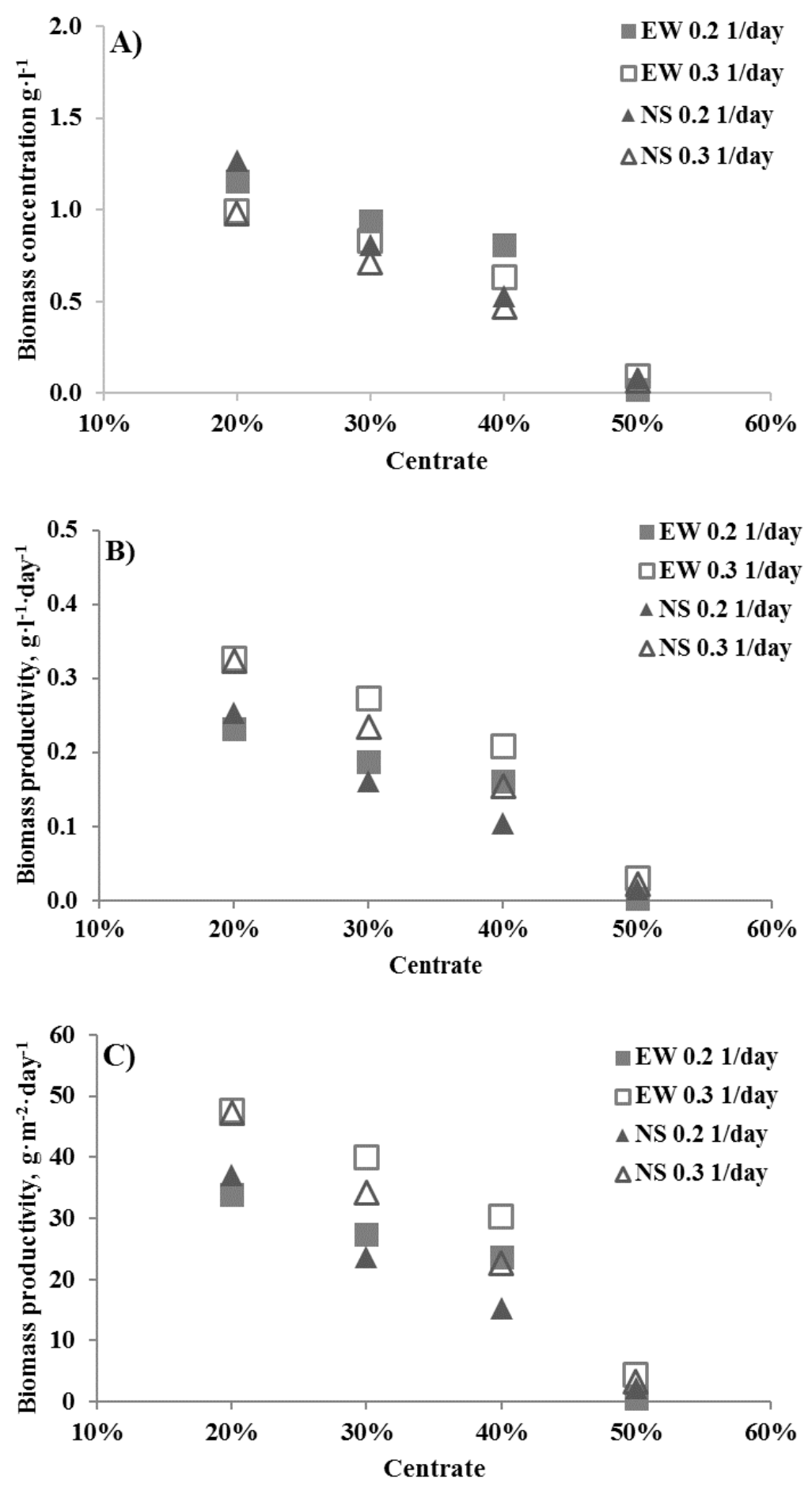

Figure 9.- Influence of the centrate percentage in the culture medium and the imposed dilution rate on biomass concentration and productivity in outdoor plastic-bag flat-panel photobioreactors. A) Biomass concentration, B) Volumetric biomass productivity, C) Land area biomass productivity. Mean values + S.D. of independent experiments performed in triplicate are shown $(\mathrm{P}<0.05)$. 

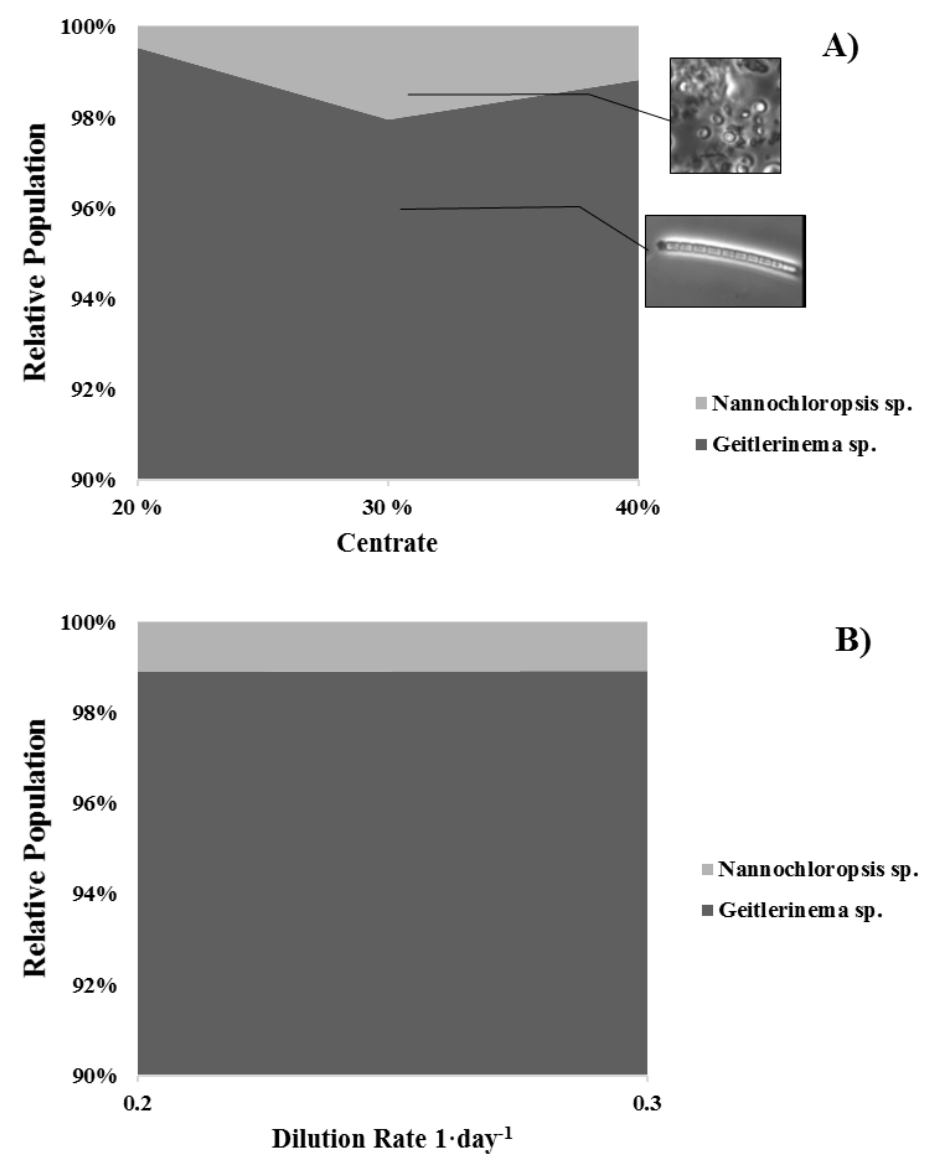

Figure 2.- Variation in the relative population of microalgae strains in the cultures with (A) the centrate percentage in the culture medium and the imposed dilution rate $(\mathrm{B})$ in outdoor plastic-bag flat-panel photobioreactors. Mean values +S.D. of independent experiments performed in triplicate are shown $(\mathrm{P}<0.05)$. 

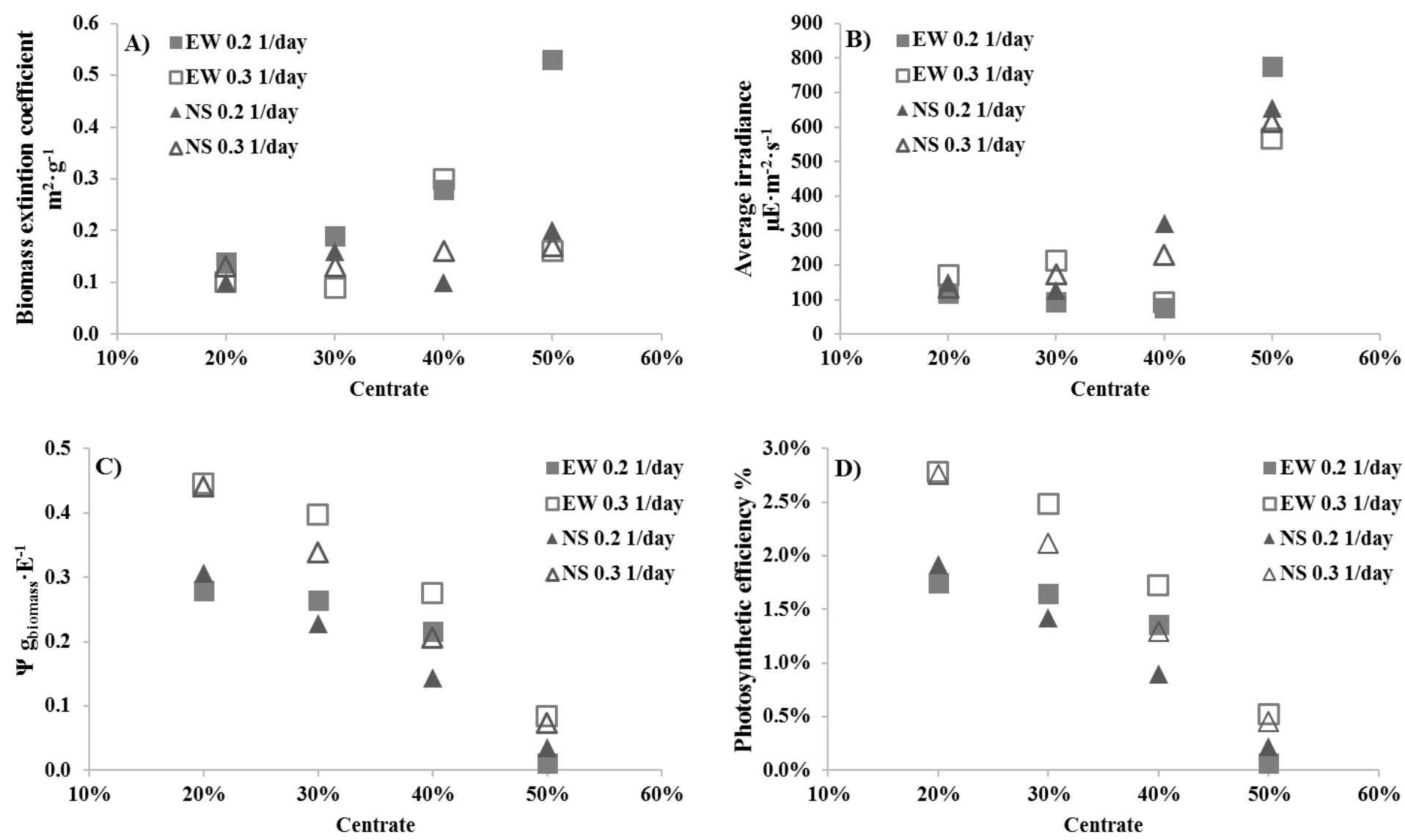

Figure 3.- Influence of the centrate percentage in the culture medium and the imposed dilution rate on the extinction coefficient of the biomass, the average irradiance inside the culture, the quantum yield and the photosynthetic efficiency in outdoor plastic-bag flat-panel photobioreactors. A) Extinction coefficient of the biomass, B) Average irradiance to which the cells are exposed inside the cultures, C) Quantum yield, D) Photosynthetic efficiency. Mean values + S.D. of independent experiments performed in triplicate are shown $(\mathrm{P}<0.05)$. 

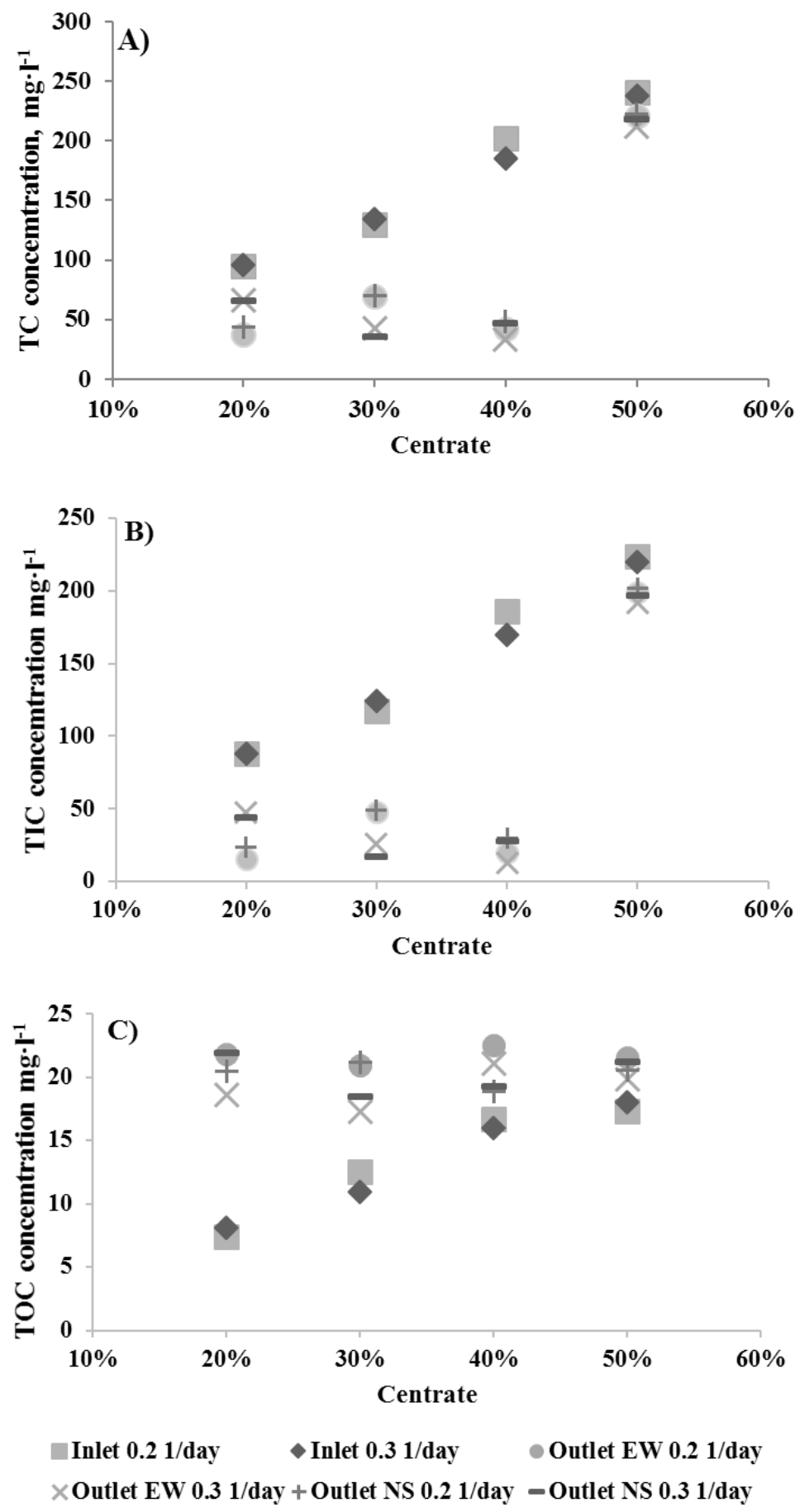

Figure 4.- Influence of the centrate percentage in the culture medium and the imposed dilution rate on the total carbon (organic and inorganic) concentration at the inlet and outlet in outdoor plastic-bag flat-panel photobioreactors. A) Total Carbon, B) Total Inorganic Carbon, C) Total Organic Carbon. Mean values + S.D. of independent experiments performed in triplicate are shown $(\mathrm{P}<0.05)$. 

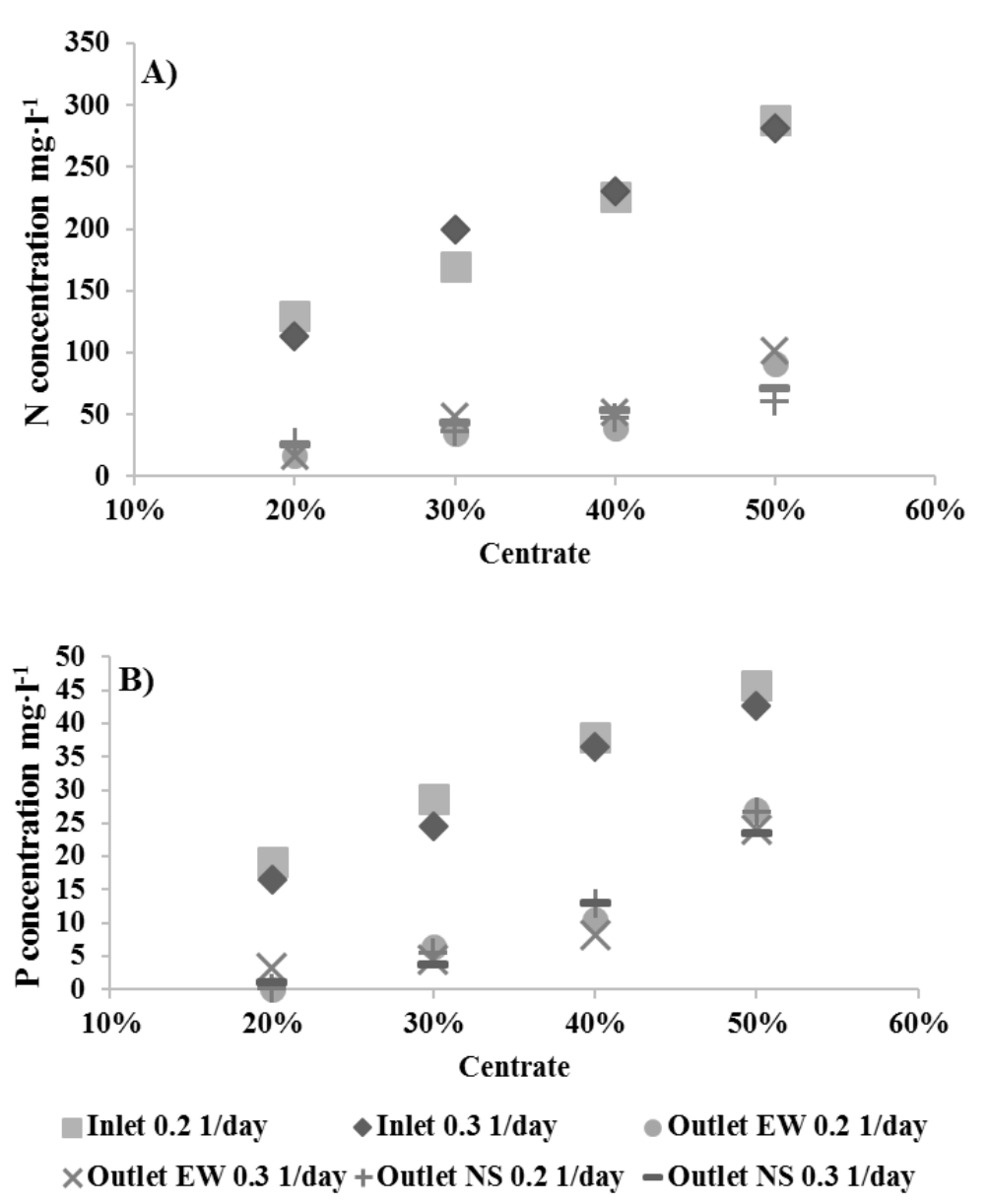

Figure 5.- Influence of the centrate percentage in the culture medium and the imposed dilution rate on the nitrogen inlet and outlet concentration, and phosphorus inlet and outlet concentration in outdoor plastic-bag flat-panel photobioreactors. A) Total nitrogen, B) Total phosphorus. Mean values + S.D. of independent experiments performed in triplicate are shown $(\mathrm{P}<0.05)$. 

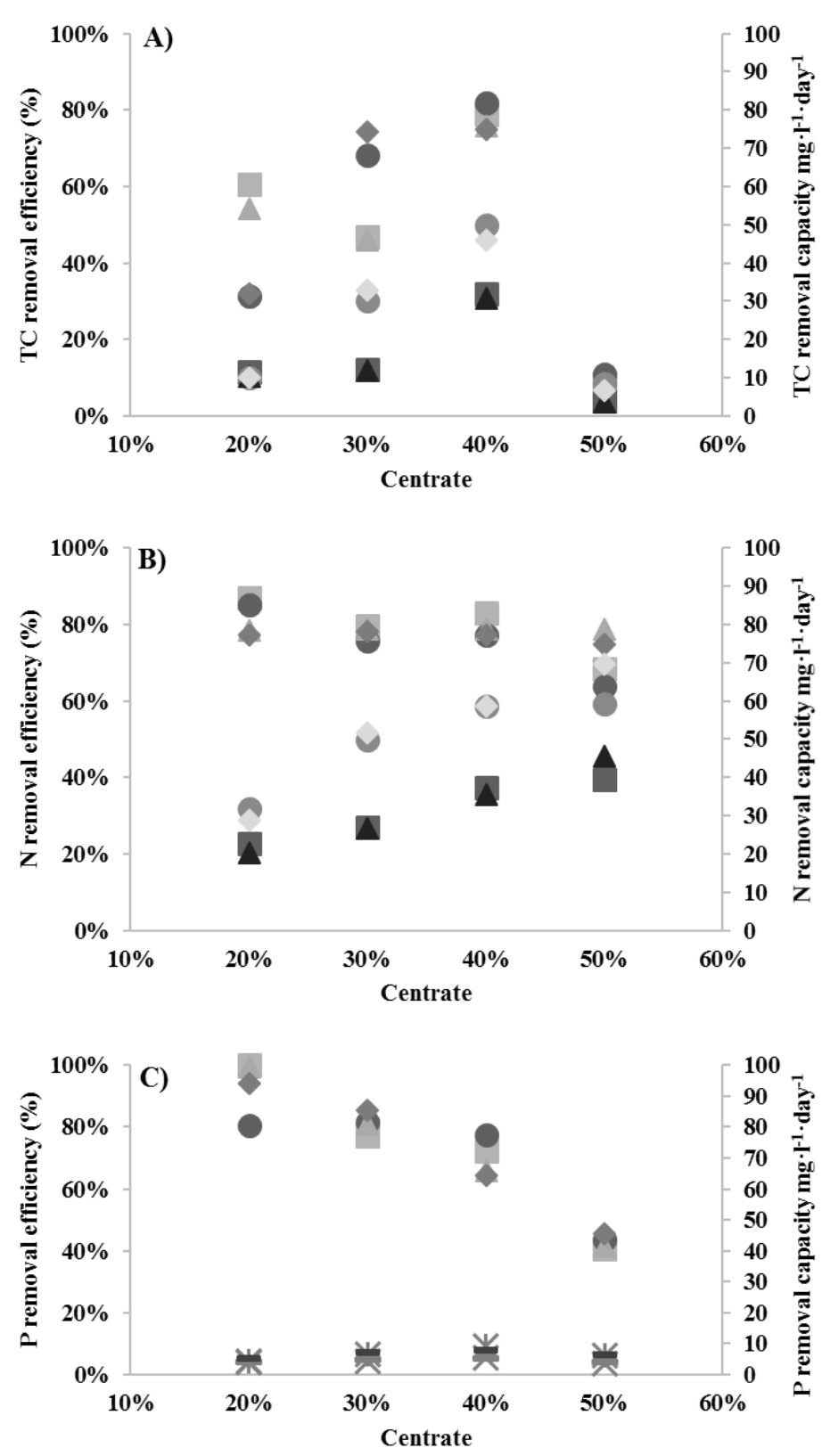

Efficiency EW 0.2 1/day $\bullet$ Efficiency EW 0.3 1/day

$\triangle$ Efficiency NS $0.21 /$ day $\bullet$ Efficiency NS $0.31 /$ day

XCapacity EW 0.2 1/day $*$ Capacity EW 0.31 1/day

- Capacity NS 0.2 1/day -Capacity NS $0.31 /$ day

Figure 6.- Influence of the centrate percentage in the culture medium and the imposed dilution rate on the carbon, nitrogen and phosphorus removal efficiency and capacity in outdoor plastic-bag flat-panel photobioreactors. A) Total carbon, B) Total nitrogen, C) Total phosphorus. Mean values + S.D. of independent experiments performed in triplicate are shown $(\mathrm{P}<0.05)$. 

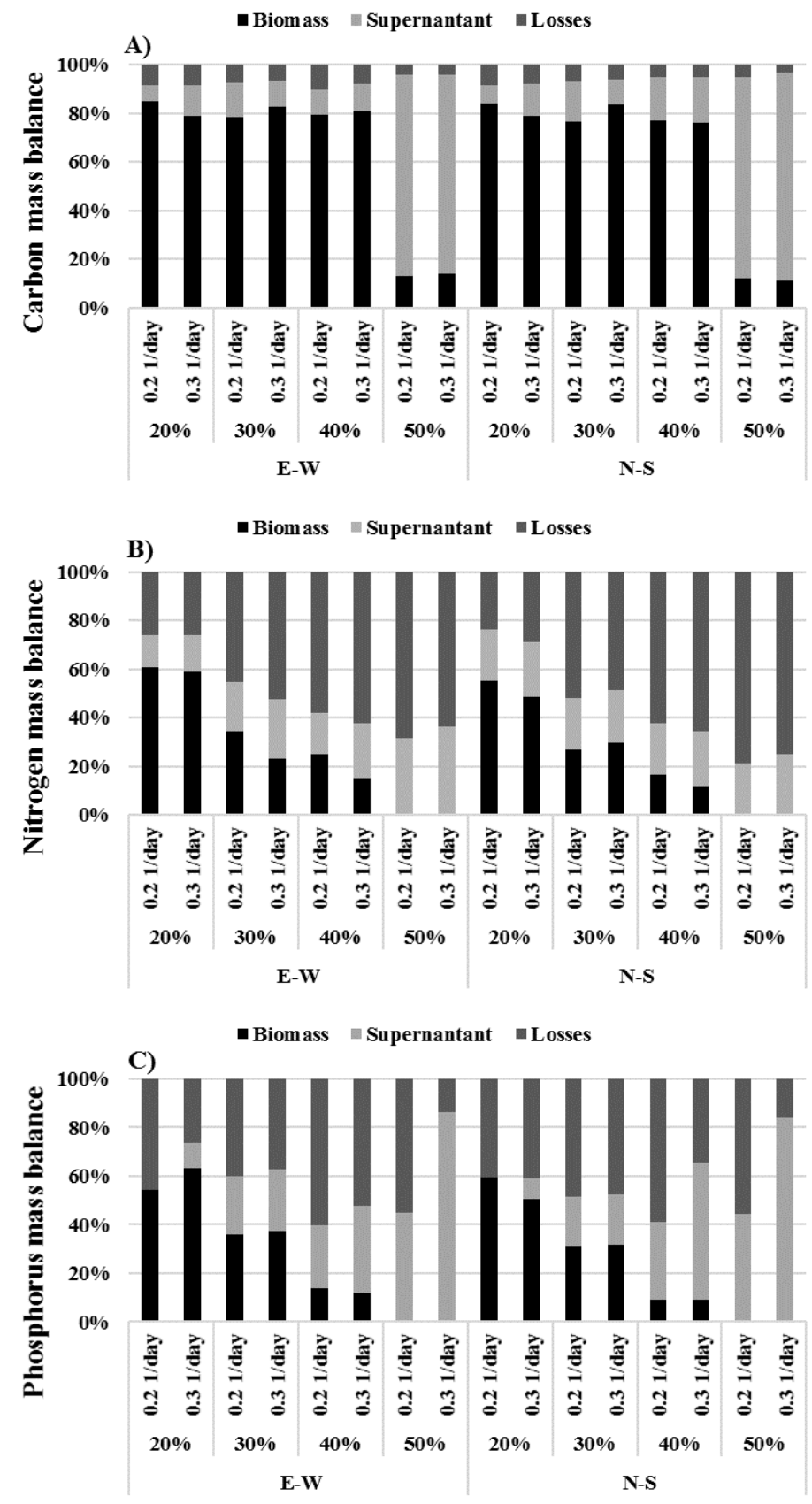

Figure 7.- Influence of the centrate percentage in the culture medium and the imposed dilution rate on the carbon, nitrogen and phosphorus mass balance of the system in outdoor plastic-bag flat-panel photobioreactors. A) Carbon, B) Nitrogen, C) Phosphorus. Mean values + S.D. of independent experiments performed in triplicate are shown $(\mathrm{P}<0.05)$. 


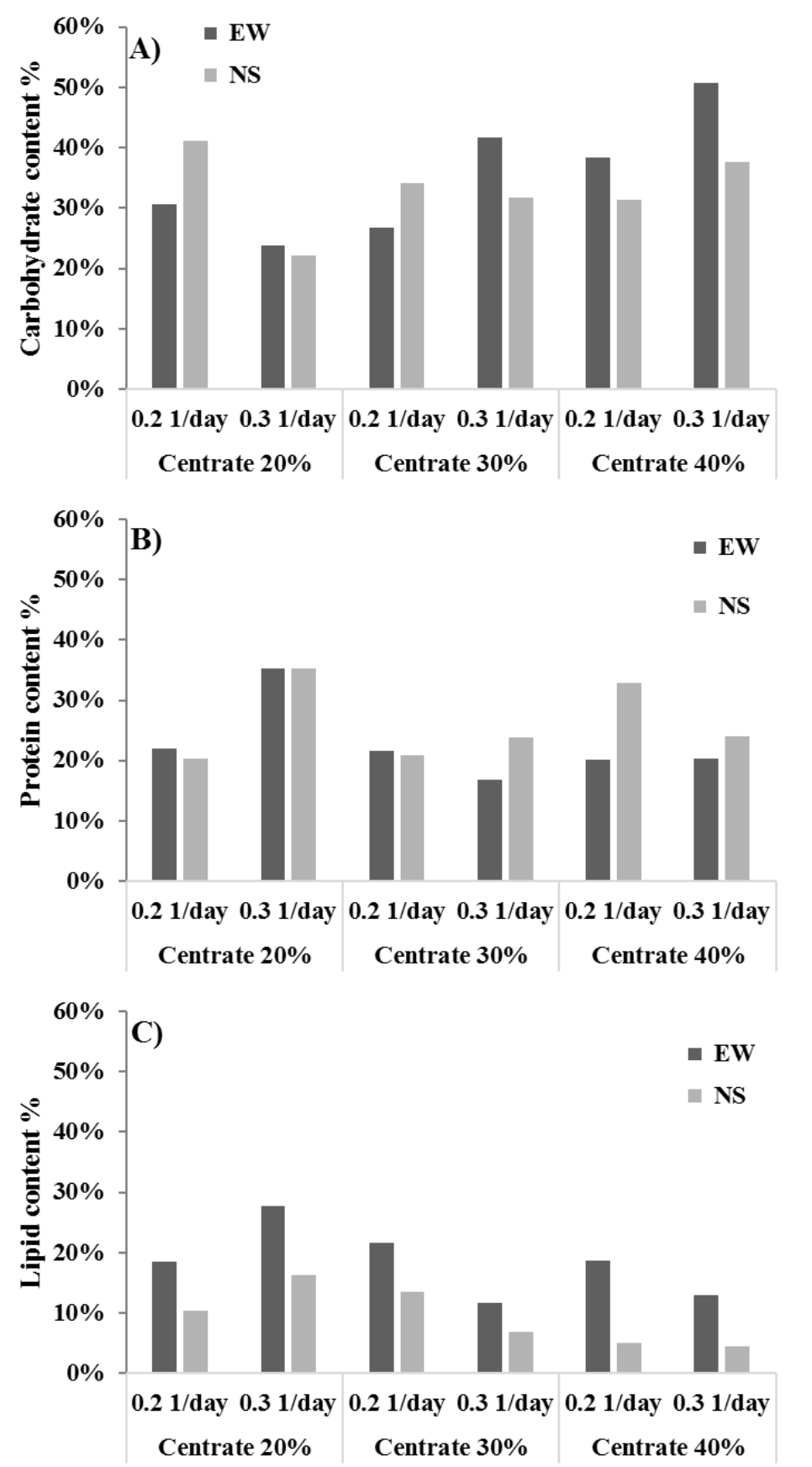

Figure 8.-Variation in the (A) carbohydrate content, (B) protein content and (C) lipid content of the microalgae biomass produced as a function of the centrate percentage in the culture medium and the imposed dilution rate in outdoor plastic-bag flat-panel photobioreactors. Mean values + S.D. of independent experiments performed in triplicate are shown $(\mathrm{P}<0.05)$. 
Table 1.- Composition of culture medium used during the experiments, which was prepared by mixing centrate from a wastewater treatment plant with seawater at different percentages. Concentration expressed as $\mathrm{mg} \cdot \mathrm{l}^{-1}$. Mean values + S.D. of independent experiments performed in duplicated along a year in six samples of 10001 each one are shown $(\mathrm{P}<0.05)$. In parenthesis the final phosphorus concentration when adding phosphorus to achieve an N:P ratio of 5.

\begin{tabular}{|c|c|c|c|c|c|}
\hline & $\begin{array}{c}\text { Centrate } \\
100 \%\end{array}$ & $\begin{array}{c}\text { Centrate } \\
50 \%\end{array}$ & $\begin{array}{c}\text { Centrate } \\
40 \%\end{array}$ & $\begin{array}{c}\text { Centrate } \\
30 \%\end{array}$ & $\begin{array}{c}\text { Centrate } \\
20 \%\end{array}$ \\
\hline$p H$ & 8.19 & 8.05 & 7.35 & 7.65 & 7.40 \\
\hline Bicarbonates & $1830 \pm 742$ & $8500 \pm 371$ & $9834 \pm 296$ & $11168 \pm 244$ & $12502 \pm 148$ \\
\hline Chlorides & $525 \pm 124$ & $10437 \pm 62$ & $12420 \pm 49$ & $14402 \pm 41$ & $16385 \pm 25$ \\
\hline Carbonates & $70 \pm 121$ & $742 \pm 60$ & $877 \pm 48$ & $1011 \pm 40$ & $1146 \pm 24$ \\
\hline Sodium & $252 \pm 74$ & $5815 \pm 37$ & $6927 \pm 30$ & $8040 \pm 24$ & $9152 \pm 15$ \\
\hline Ammonium & $732 \pm 234$ & $366 \pm 117$ & $293 \pm 94$ & $219 \pm 77$ & $146 \pm 47$ \\
\hline Calcium & $133.0 \pm 18$ & $284 \pm 9$ & $315 \pm 7$ & $345 \pm 6$ & $375 \pm 4$ \\
\hline Potassium & $99.6 \pm 5.0$ & $260.7 \pm 2.5$ & $292 \pm 2$ & $325 \pm 2$ & $357 \pm 2$ \\
\hline Magnesium & $88.0 \pm 1.0$ & $728.0 \pm 0.5$ & $856 \pm 2$ & $984 \pm 2$ & $1112 \pm 2$ \\
\hline Sulphates & $38.5 \pm 7.3$ & $1453.0 \pm 3.6$ & $1735 \pm 3$ & $2018 \pm 2$ & $2301 \pm 2$ \\
\hline Phosphorus & $\begin{array}{c}14.1 \pm 3.9 \\
(146.1 \pm 4.1)\end{array}$ & $\begin{array}{c}7.0 \pm 1.9 \\
(73.2 \pm 3.5)\end{array}$ & $\begin{array}{c}5.6 \pm 1.5 \\
(58.6 \pm 3.1)\end{array}$ & $\begin{array}{c}4.36 \pm 1.2 \\
(48.2 \pm 2.3)\end{array}$ & $\begin{array}{c}4.2 \pm 0.8 \\
(43.8 \pm 1.3)\end{array}$ \\
\hline Boron $(B)$ & $0.28 \pm 0.09$ & $0.14 \pm 0.08$ & $0.11 \pm 0.08$ & $0.08 \pm 0.07$ & $0.06 \pm 0.04$ \\
\hline Zinc $(Z n)$ & $0.10 \pm 0.07$ & $0.05 \pm 0.04$ & $0.04 \pm 0.03$ & $0.03 \pm 0.02$ & $0.02 \pm 0.01$ \\
\hline $\operatorname{Iron}(F e)$ & $0.04 \pm 0.01$ & $0.02 \pm 0.01$ & $0.02 \pm 0.01$ & $0.01 \pm 0.01$ & $0.01 \pm 0.01$ \\
\hline Manganese (Mn) & $0.02 \pm 0.01$ & $0.01 \pm 0.01$ & $0.01 \pm 0.01$ & $0.01 \pm 0.01$ & $0.00 \pm 0.01$ \\
\hline Nitrates & $6.55 \pm 0.62$ & $3.28 \pm 0.31$ & $2.62 \pm 0.26$ & $2.0 \pm 0.22$ & $1.3 \pm 0.13$ \\
\hline Copper $(\mathrm{Cu})$ & $0.08 \pm 0.01$ & $0.04 \pm 0.01$ & $0.03 \pm 0.01$ & $0.02 \pm 0.01$ & $0.02 \pm 0.01$ \\
\hline
\end{tabular}


